\title{
The dissonance Mutation at the no-on-transient-A Locus of $D$. melanogaster: Genetic Control of Courtship Song and Visual Behaviors by a Protein with Putative RNA-binding Motifs
}

\author{
Katherine G. Rendahl, ${ }^{1}$ Kevin R. Jones, ${ }^{2, a}$ Shankar J. Kulkarni, ${ }^{1, b}$ Stephanie H. Bagully, ${ }^{1}$ and Jeffrey C. Hall ${ }^{1}$ \\ 'Department of Biology, Brandeis University, Waltham, Massachusetts 02254 and 2Department of Molecular and Cellular \\ Biology and Howard Hughes Medical Institute, University of California, Berkeley, California 94720
}

Genetic and molecular results are here presented revealing that the dissonance (diss) courtship song mutation is an allele of the no-on-transient-A (nonA) locus of Drosophila melanogaster. diss (now called nonA diss) was originally isolated as a mutant with aberrant pulse song, although it was then noted to exhibit defects in responses to visual stimuli as well. The lack of transient spikes in the electroretinogram (ERG) and optomotor blindness associated with nonAdiss are shown to be similar to the visual abnormalities caused by the original nonA mutations. nond diss failed to complement either the ERG or optomotor defects associated with four other nonA mutations. However, all four of these nonA mutants-which were isolated on visual criteria alone-sang a normal courtship song. nonA diss complemented at least three of the nonA mutations with regard to the singing phenotype, as assessed by a new method for temporal analysis of the male's pulse song. Both visual and song abnormalities caused by non $A^{\text {diss }}$ were rescued by $P$-element-mediated transformation with overlapping 11 and 16 kilobase (kb) fragments of genomic DNA (originally cloned from the nonA locus by Jones and Rubin, 1990). Analysis of behavioral phenotypes in transformed flies carrying mutagenized versions of the $11 \mathrm{~kb}$ genomic fragment (in a nonAdiss genomic background) localized the rescuing DNA to a region containing an open reading frame that encodes a polypeptide (NONA) with similarity to a family of RNA-binding proteins. Immunohistochemical determination of NONA's spatial and temporal expression revealed that it is localized to the nuclei of cells in many neural and non-neural tissues, at all stages of the life cycle after very early in development. Genetic connections between the control of two quite different behaviors-re-

\footnotetext{
Received May 22, 1991; revised Sept. 9, 1991; accepted Sept. 11, 1991.

We thank David A. Wheeler for helping to analyze the NONA protein sequence; Eric K. Neumann for his development of LIFESONG software; Adam S. Bernstein for his regression programs; Tim Tully for help with the statistics; Harald Saumweber and Ralf Stanewsky, plus Liqun Luo and Kalpana White, for communications of unpublished results; William L. Pak for such communication and for fly stocks; Gerald M. Rubin for support of K.R.J. and for providing reagents Bruce Kimmel for advice on the antibody work; and Linda Martin-Morris, Susan DeSimone, Valerie Merrill, and Michael Rosbash for comments on the manuscript. This study was supported by NIH Grant RO1 GM-21473 and NIH Neurobiology Training Grant T32 NS-07292.

Correspondence should be addressed to Jeffrey C. Hall, Department of Biology, 235 Bassine Building, Brandeis University, Waltham, MA 02254.

a Present address: Department of Physiology and Howard Hughes Medical Institute, University of California, San Francisco, CA 94143.

b Present address: Worcester Foundation for Experimental Biology, Shrewsbury, MA 01545

Copyright (c) 1992 Society for Neuroscience $0270-6474 / 92 / 120390-18 \$ 05.00 / 0$
}

productive and visual-are discussed, along with precedences for generally expressed gene products playing roles in specific behaviors.

The no-on-transient- $A$ (non $A$ ) mutants are among many in Drosophila melanogaster with defects in the functioning of the visual system (reviewed by O'Tousa, 1990; Pak, 1991; Smith et al., 1991). The non $A$ visual phenotype involves multiple defects, as assayed electrophysiologically and behaviorally, nonA was first identified by Pak et al. (1970) and Hotta and Benzer (1970) in screens for phototaxis mutants and subsequently in a screen for flies deficient in optomotor responses (Heisenberg, 1971). Kulkarni et al. (1988) isolated an additional nearby mutation, called dissonance (diss), by searching for (chemically induced) courtship song mutants; this one turned out to exhibit visual defects as well. One purpose of the present study was to determine if diss is a nonA allele.

The non $A$ mutants are defective in the electroretinogram (ERG) and in optomotor responses. Phototaxis is not severely impaired in the mutants; the non $A^{H^{2}}$ mutant exhibits an approximately $50 \%$ decrease in "slow phototaxis" (Heisenberg, 1972), and diss showed about the same level of deficiency in similar tests (Kulkarni et al., 1988). Pak et al. (1970) noted that nonA's ERG was aberrant, lacking the light-on and light-off transient spikes, while the sustained depolarization was normal (Fig. 1A). A variety of evidence indicates that these potentials arise from the lamina, the optic ganglion just proximal to the eye (Pak, 1975; Coombe, 1986; Coombe and Heisenberg, 1986), whereas the maintained component is a summation of light-elicited generator potentials in the photoreceptors of the compound eye. Thus, the absence of ERG transient spikes in a mutant such as nonA implies either that transmission of the light signal to the neurons in the lamina is prevented or that excitation of these laminar cells does not occur. Hotta and Benzer (1970) determined, more specifically, that the $n o n A^{B S 18}$ mutation's ERG defect was due to a primary abnormality in the photoreceptors, yet this conclusion was based on analysis of such a small number of genetic mosaics that the results could not rule out a "focus" separable from the eye.

Indeed, optomotor responses of nonA mutants suggest that they have a relatively central defect in their visual system. For Drosophila, the optomotor test is an assay of the fly's tendency to follow movement in its environment, such as rotating stripes (Götz, 1964), and must reflect a synthesis of the input from at least two photoreceptors (Pak, 1975). Heisenberg (1972) characterized the flying and walking optomotor behavior of non $A^{H 2}$; this was further refined by Heisenberg and Buchner (1977). 
A

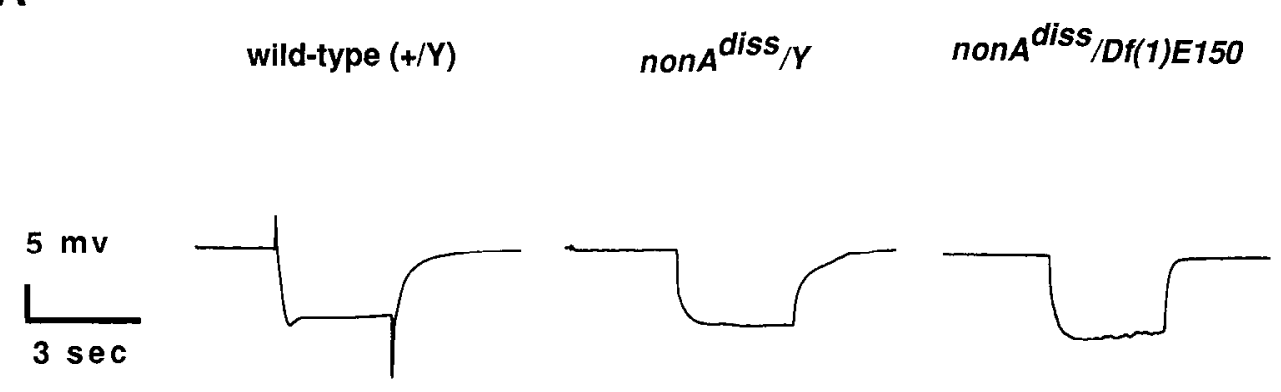

B

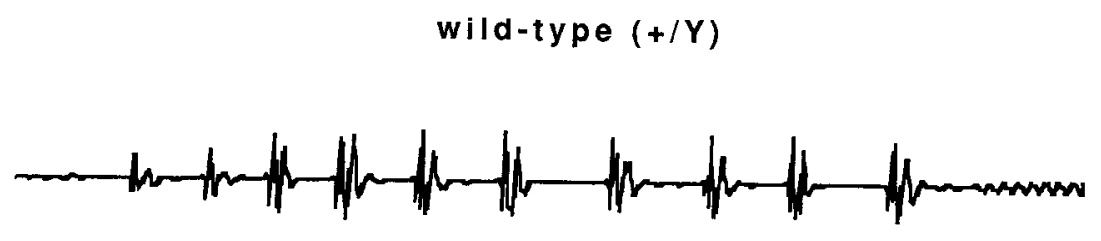

$50 \mathrm{msec}$

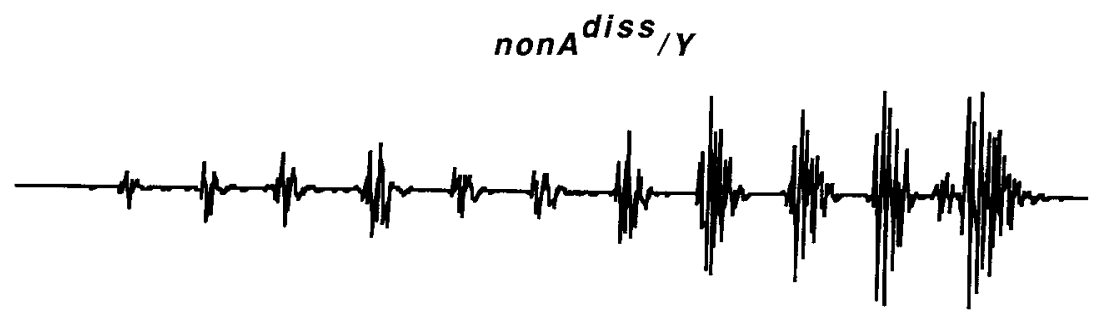

Figure 1. Physiological and behavioral defects of the non $A^{d i s s}$ mutant. $A$, ERGs from wild-type (Canton-S), non $A^{\text {diss }} f / Y$ male and non $A^{\text {diss }}$ $f / D f(1) E 150$ mutant flies (the latter two carrying the forked marker). Note the light-on and -off transient spikes present in the wild-type trace, which are lacking in those from the two mutant types. $B$, Pulse song trains from a wildtype, a non $A^{d i s s} f / Y$, and a non $A^{d i s s}$ $f / D f(1) E 150$ male (the latter homozygous for tra). The wild-type and nonA diss $f / Y$ trains are shown beginning with the first pulse, whereas the non $A^{\text {diss }}$ $f / D f(1) E 150$ example is taken from approximately $500 \mathrm{msec}$ into a train; the wild-type song is uniform in polycyclicity and amplitide, while the mutant songs increase in both of these parameters as the trains proceed.

These investigators showed that this mutant's behavioral defects, mediocre phototaxis and a much reduced optomotor turning response, are due to faulty input through photoreceptors R1-6. Since the generator potentials of R1-6 appear to be normal in nonA mutants (e.g., Fig. $1 A$, Table 2), visual pathways proximal to these photoreceptors would appear to be affected by such mutations. Examining further details of the optomotor responses of $n o n A^{H 2}$ showed the mutant specifically not to react to front-to-back, or progressive, motion, while its reaction to regressive motion was intact (Heisenberg, 1972). Once more, it seems likely that this behavioral aberration is caused by defects in the structure or function of visual system elements postsynaptic to the photoreceptors.

An additional mutant phenotype associated with nonA, but only with its diss allele, is aberrant courtship song. This singing behavior is performed when the male extends and vibrates one wing or the other while orienting toward the female (reviewed in Burnet and Connolly, 1974; Ewing, 1977). The wild-type song is comprised of sine song, a low-frequency hum, interspersed with bouts of pulse song, which consists of mono- to tricyclic signals of higher amplitude and intrapulse frequency than the hums (e.g., Cowling and Burnet, 1981; Kulkarni and Hall, 1987; Wheeler et al., 1988; see also Fig. 1B). In wild-type $D$. melanogaster, the interpulse interval (IPI) is about $35 \mathrm{msec}$ (e.g., Cowling and Burnet, 1981; Wheeler et al., 1989). The diss allele of the nonA gene (Kulkarni et al., 1988) is one of two single-gene mutations isolated by virtue of their effects on the courtship song of D. melanogaster (see also Kulkarni and Hall, 1987). nonAdiss causes the pulse song to become variable within a train of pulses; the mutant song usually increases in poly- 


\begin{tabular}{|c|c|c|}
\hline Chromosomal aberration & $\begin{array}{l}\text { Cytological } \\
\text { breakpoints }\end{array}$ & References \\
\hline \multicolumn{3}{|l|}{ Simple duplication } \\
\hline$T(1 ; 2) r^{+75 c}$ & $14 \mathrm{~B} 13$ to $15 \mathrm{~A} 9$ & Ganetzky and Wu, 1982; Schalet, 1986 \\
\hline \multicolumn{3}{|l|}{ Deleted duplication } \\
\hline$T(1 ; 4)+D f(1) 81 k 21 e$ & $14 \mathrm{~B} 5-18$ to $15 \mathrm{~A} 5$ & Falk et al., 1984 \\
\hline \multicolumn{3}{|l|}{ Interstitial deletion } \\
\hline$D f(1) E 150$ & $14 \mathrm{~B} 3-4$ to $14 \mathrm{E}$ & $\begin{array}{l}\text { B. H. Judd, unpublished observations; S. Banga } \\
\text { and J. B. Boyd, unpublished observations }\end{array}$ \\
\hline
\end{tabular}

These aberrations were used in crosses performed to localize the non $A^{\text {diss }}$ mutation. The interstitial deletion, when heterozygous with any other X chromosome, causes a deleterious Minute phenotype, owing to the absence of a segment of the X chromosome in which $M(1) 14 C$ maps (see Lindsley and Zimm, 1990). The deleted duplication (involving a segment of the $\mathrm{X}$ chromosome translocated to chromosome 4 , from which the indicated region was subsequently deleted) defines the proximal boundary (Fig. 2) of the nonA-containing interval (owing to the duplication's coverage of non $A^{\text {diss. }}$ see Tables 2,3 ). The simple duplication, involving a piece of the $X$ chromosome translocated to chromosome 2 , which also covers diss, defines the locus's distal boundary [the leftmost breakpoint of this aberration (Fig. 2) indeed was molecularly mapped to a more distal site than that of the deleted duplication (Jones and Rubin, 1990)]. Thus, nonA would map within 14B13-18 (assuming that the distal breakpoint in the deleted duplication is nearer to $14 \mathrm{~B} 18$ than to 14B5). This is a mild discrepancy from the independent mapping of nonA, based on in situ hybridization of labeled DNA probes to polytene chromosomes, within the interval 14C1-2 (Besser et al., 1990; Jones and Rubin, 1990), but the difference is probably due to the difficulty in resolving (either in breakpoint determinations or when reading the precise site of hybridization signals) the very faint chromosome bands in the proximal $14 \mathrm{~B} /$ distal $14 \mathrm{C}$ region of the $\mathrm{X}$ chromosome.

cyclicity and amplitude as a train of pulses proceeds (Kulkarni et al., 1988). The present report shows that the song phenotype produced by a fly carrying non $A^{\text {diss }}$ heterozygous with a deletion of the locus is even more extreme, with up to 100 cycles per pulse (CPP) (Fig. 1B). Although some song pulses produced by non $A^{\text {diss }}$ males are superficially normal, the mutant exhibits aberrations in several of the parameters that have been described for wild-type. For example, Fourier analysis revealed additional harmonic frequencies not present in wild-type pulses, and the IPIs in $n o n A^{\text {diss }}$ songs were distributed over an anomalously large range (Wheeler et al., 1989).

Genetic mapping performed on the X-chromosomal nonA mutations revealed non $A^{H 2}$ and $n o n A^{P 14}$ to be localized at 52 map units (Pak et al., 1970; Heisenberg, 1971, 1972). non $A^{P 49}$ and $n o n A^{P 60}$ were also mapped to this locus (W. L. Pak, personal communication); diss was as well and, in addition, to a distal region within cytological interval $14 \mathrm{C}$ of the $\mathrm{X}$ chromosome (Kulkarni et al., 1988). This localization has been refined by applying an additional chromosome aberration and by reinterpretation of cytological breakpoints in light of new molecular mapping data (cf. Jones and Rubin, 1990). We have also comapped the non $A$ and non $A^{\text {diss }}$ mutations to the narrowest possible cytological interval (given the available aberrations), which spans 20 kilobases $(\mathrm{kb})$ of X-chromosomal DNA (Jones and Rubin, 1990). In addition, we show that non $A^{d i s}$ fails to complement defects associated with other non $A$ mutations in the ERG and optomotor tests. However, the latter, in combination with non $A^{\text {diss }}$, were normal (or nearly so) with respect to courtship song. Males hemizygous for nonA mutations other than diss also produced a normal song.

Recently, the region including the non $A$ gene has been cloned in a chromosomal walk; the locus was molecularly delimited, by visual-response tests of P-element-mediated germline transformants, to an approximately $9 \mathrm{~kb}$ segment of the DNA within cytological region 14 of the $\mathrm{X}$ chromosome (Jones and Rubin, 1990). We now show that the courtship and visual phenotypes of non $A^{\text {diss }}$ can be rescued by the same genomic DNA that rescued the visual defects of non $A^{H 2}$. Further dissection of this 9 $\mathrm{kb}$ region was carried out by introducing mutagenized versions of the original genomic construct into flies carrying non $A^{\text {diss. }}$.
Another set of investigators cloned the nonA gene (Besser et al., 1990), based on a very different biological perspective from that of Jones and Rubin (1990). At about the same time, both Besser et al. (1990) and we (see Rendahl and Hall, 1991, from a conference that occurred in October, 1990) observed that two approximately 90 amino acid regions of the non $A$ gene are similar to a large family of proteins containing RNA-binding motifs. Details of these protein "domain homologies" are described in the present report. We also show that this gene's expression is widespread throughout development, both temporally and spatially. The pleiotropic effects of nonA's diss allele are discussed in the context of emerging results on the intrinsic nature and expression of the products encoded by this gene.

\section{Materials and Methods}

General. Flies were raised on a medium of cornmeal, agar, molasses, yeast, and the mold inhibitor Tegosept, at $25^{\circ} \mathrm{C}$ under $\sim 50 \%$ humidity and $12 \mathrm{hr}$ light $/ 12 \mathrm{hr}$ dark cycling conditions.

Mapping and complementation tests. Crosses were carried out to generate flies in which to test various chromosome aberrations with breakpoints near the non $A^{\text {diss }}$ locus, for coverage of this mutation's effects. Certain of the aberrations used previously (Kulkarni et al., 1988), plus an additional one, were applied in the present study. The simple duplication and the deleted one (Table 1) were tested for their behavioral effects in a non $A^{\text {diss }}$ haplo-X (male) genetic background, whereas the interstitial deletion (Table 1) was tested over nond diss in a diplo-X transformer (XX; tra/tra) background (cf. Sturtevant, 1945). The XX homozygous tra type is a "pseudomale," which behaves essentially as does an XY (tra or tra ${ }^{+}$) fly (e.g., Kulkarni and Hall, 1987).

Kulkarni et al. (1988) reported cytogenetic data that nominally defined the chromosomal region including dissonance as having a proximal boundary at $14 \mathrm{C} 4-5$ and its distal one at $14 \mathrm{Cl}-2$. Certain of these chromosome aberrations (Table 1) were reapplied here, with more extensive techniques for song analysis (see below) than were used by Kulkarni et al. (1988). Also, the mapping of non $A^{\text {diss }}$ was refined to a narrower cytological region using an additional aberration, in combination with molecular breakpoint determinations (Table 1; cf. Jones and Rubin, 1990).

Complementation tests were carried out between non $A^{\text {diss }}$ and four mutations-non $A^{H 2}$, non $A^{P 14}$, non $A^{P 49}$, and $n o n A^{P 60}$-in order to examine allelic relationships between the song and the visual mutants. Pseudomales heterozygous for two given mutations were assayed for electroretinogram, optomotor, and courtship song phenotypes. To rule out mere dominance associated with one of the variants in the double heterozygote, mutant-over-normal flies were tested and compared to 


\begin{tabular}{|l|c|c|c|c|}
\hline 3456789101112131415161718 & 12345678 & 1234 & 123456 \\
$B$ & C & D & $E$ & \\
\hline 4 & & & & 14
\end{tabular}

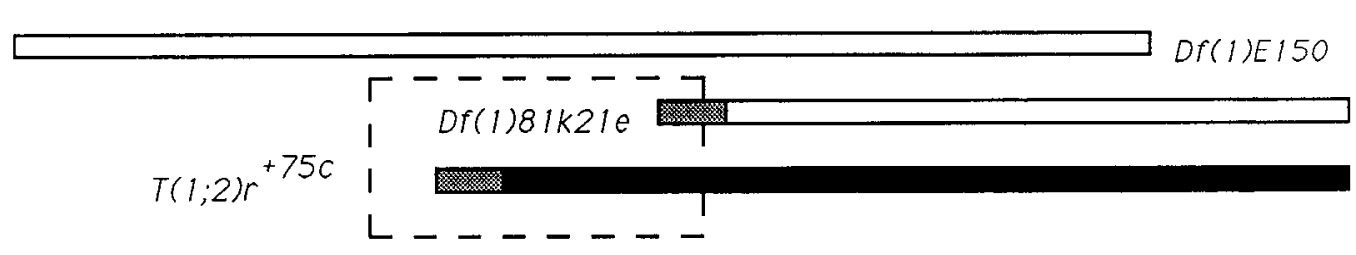

B

$$
T(1 ; 2) r^{+75 c} \quad \text { Df }(1) 81 \mathrm{k} 21 \mathrm{e}
$$
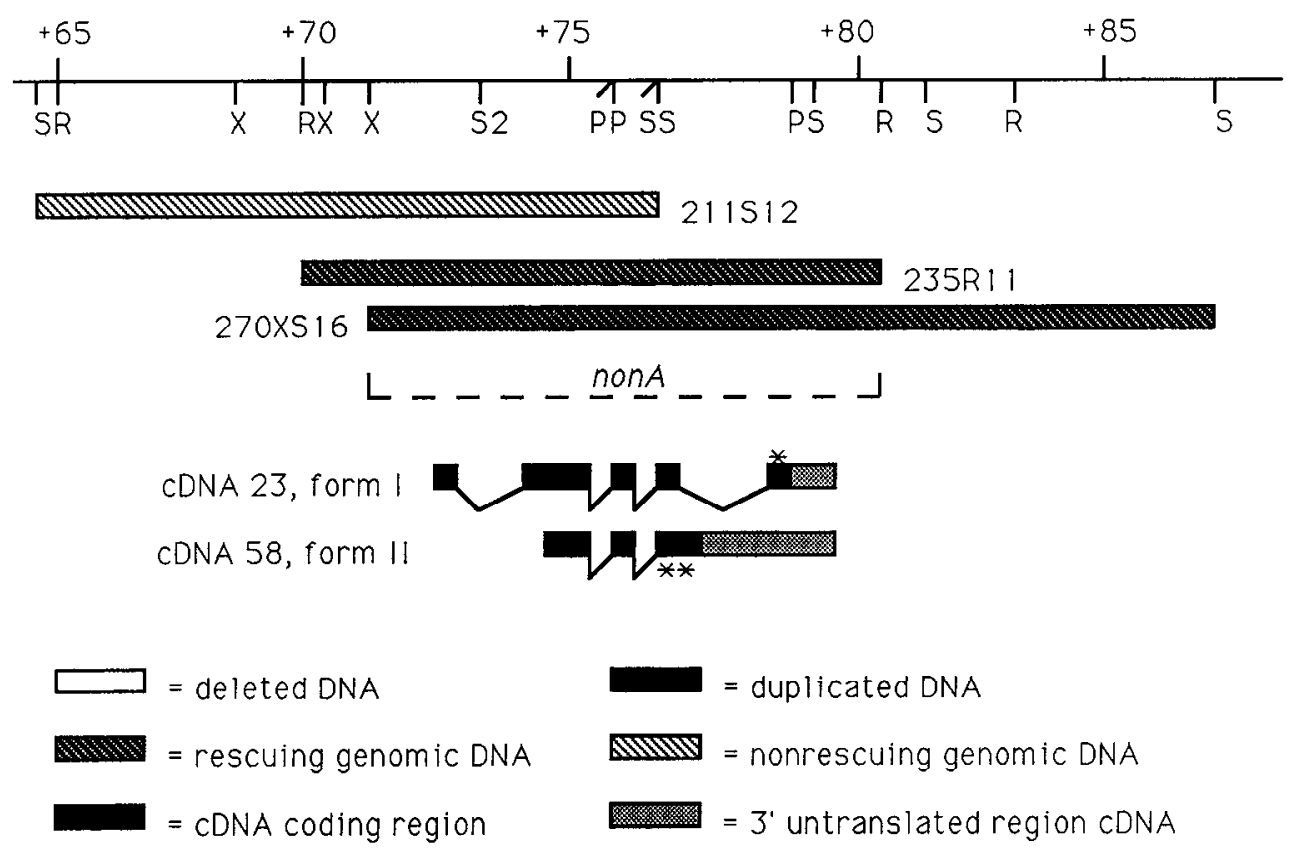

Figure 2. Cytogenetic and molecular mapping of the X-chromosomal non $A$ region. $A$, A genetic map of this region, illustrating the cytological bands of 14B$\mathrm{E}$ of the $\mathrm{X}$ chromosome, above, and the relevant chromosomal aberrations below (open bars, deletions; solid bar, translocation/duplication; shaded bars, regions of breakpoint position uncertainty). The dashed box indicates the non $A$ region between the distal cytological breakpoint $T(1 ; 2) r^{+75 c}$ and the proximal breakpoint $D f(1) 81 \mathrm{k} 21 \mathrm{e}$, as previously mapped by Jones and Rubin (1990). $B$, Enlargement of the boxed region seen in $A$ shows further delimitation of the nonA gene by transformation rescue with two genomic DNA fragments of the $14 \mathrm{~B}-\mathrm{C}$ region; these overlap by $9 \mathrm{~kb}$ (dark hatched bars), as demonstrated by Jones and Rubin (1990). The positions of the two known nonA cDNA types " 23 " and " 58 " and their intron-exon boundaries are also indicated (shaded bars); the RNAs corresponding to the cDNAs are entirely encoded within the area defined by transformation rescue (cf. Jones and Rubin, 1990). Type 23 is defined as encoding the NONA form I polypeptide; 58 , form II (see text). The single asterisk designates the approximate site of the "1-STOP" in vitro mutation; the double asterisk, that of the "2-STOP" mutation (see Materials and Methods; see also Table 5). The restriction sites are abbreviated as follows: $P$, Pst I; $R$, EcoR I; $S$, Sal I; $S 1$, Sac I; $S 2$, Sac II; $X, \mathrm{Xba}$ I. wild-type males (see normal controls sections of Tables 2,3); for these controls, the $n o n A^{+}$-bearing chromosomes were from a Canton-S (wildtype) stock or derived from a stock carrying the multiply inverted $\mathrm{X}$-chromosomal balancer $F M 7 \mathrm{a}$. Further complementation tests involved non $A^{d i s s}$ and mutations at two nearby vital loci; thus, diplo-X adults heterozygous for the song-visual mutation and either $l(1) 9-21$, l(1)i19e, or $l(1) i 19 e^{2}$ (the latter two being allelic to each other) wcrc tested for singing behavior and optomotor response.

Transgenic flies. High-resolution localization of the dissonance allele was carried out by behaviorally testing germline transgenics. These had been generated by P-element transformation, using fragments of genomic DNA cloned from the cytologically defined nonA region (Jones and Rubin, 1990). Such fragments were obtained in a chromosomal walk and span approximately 20 kilobases of proximal 14B/distal $14 \mathrm{C}$ on the X chromosome; the DNA fragments were transduced into various autosomal locations (Jones and Rubin, 1990). For the present study, these "inserts," marked with $r y^{+}$, were introduced into an "outcrossed" non $A^{d i s s} ; r y^{506}$ male genetic background. This outcrossed line was created in an attempt to restore a robust mutant song phenotype to non $A^{\text {diss }}$ strains, in which the phenotypic defects were seen to be "weakening" (i.e., moving toward normality), after years of mass culturing. It was felt that a maximal discrimination between the songs of $n o n A^{\text {diss }}$ versus non $A^{+}$males would allow optimal separation of what might be subtly different phenotypes in flies containing the various insert types. Therefore, possible mutant-modifying element(s) on the $\mathrm{X}$ chromosome were removed by recombination of a nonA diss-bearing $\mathrm{X}$, to replace with normal alleles the garnet $\left(g^{2}\right)$ and scalloped $(s d)$ markers that had becn linked just distal to nonA (cf. Kulkarni et al., 1988). The resulting flies (including restoration of homozygosity for $r y^{506}$ ) in fact demonstrated the severe song phenotype as originally observed in this mutant.

Three genomic insert types were tested: an $11 \mathrm{~kb}$ Eco RI fragment, a $16 \mathrm{~kb}$ Xba I-Sac I fragment, and as a control, a $12 \mathrm{~kb}$ Sal I fragment distal to nonA (Fig. 2). Analyses of these transgenics were originally carried out by testing them for rescue of $n o n A^{H 2}$, which resulted in restoration of ERG transients by the first two of them but not the third one (Jones and Rubin, 1990). For each construct type, we behaviorally assayed independent transformant lines (Tables 4,5 ), to guard against effects of the position of insertion on the expression of the transduced DNA.

Two engineered variants of the $11 \mathrm{~kb}$ Eco RI fragment, transformed 
A

CYCLES PER PULSE

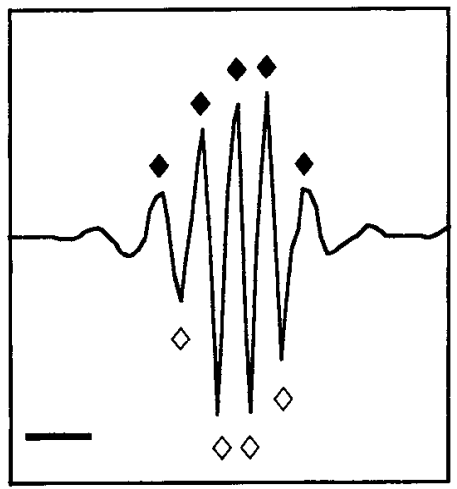

B

INTRAPULSE FREQUENCY

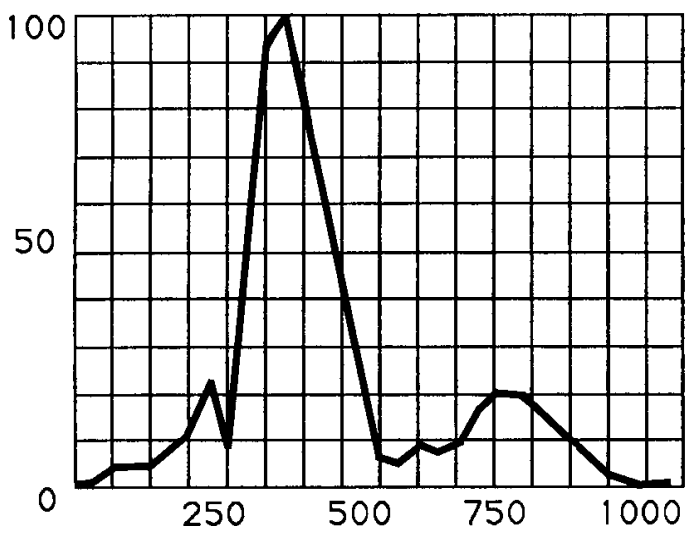

Figure 3. Cycles and intrapulse frequencies of Drosophila song signals. $A$, In this "tone pulse" from a non $A^{d i s s}$ male, the pulse boundaries are defined as the points where the pulse envelope, generated via a Butterworth filter (see Wheeler et al., 1988), reach $25 \%$ of the pulse's maximum, or the value of the background noise if this is higher. Within the pulse, the number of crossings of the $x$-axis are counted and this number divided by two to calculate the cycle number (for a more detailed discussion, see Bernstein et al., 1991). Thus, each cycle consists of a peak and a trough, as indicated by the solid and open diamonds, respectively, for the non $A^{d / s s}$ pulse shown. This pulse has a CPP value of 4.5 . Calibration, 5 msec. $B$, In this fast Fourier transform of the pulse shown in $A$ (cf. Wheeler et al., 1988), the IPF or modal frequency value of the fast Fourier transform is indicated by the peak at $100 \%$ energy. The vertical axis represents the percentage energy level, and the $\mathrm{x}$-axis, the frequency value. The IPF value in this case is approximately $375 \mathrm{~Hz}$.

into the fly's genome by Jones and Rubin (1990), were assessed here for coverage of $n o n A^{d i s s}$ 's effects by performing ERG, optomotor, and courtship song analyses. These transformants were previously tested for the ability to rescue the ERG phenotype of $n o n A^{H 2}$ (Jones and Rubin, 1990). They had first isolated two different nonA cDNAs from an adult "head library," having unique 33 and 35 amino acid sequences at their carboxy termini and coding for putative NONA proteins called form I and form II, respectively (see Results and Fig. 2). Conceptual translation of the complete open reading frame (ORF) of the form I cDNA predicts a protein of 700 amino acids. [Form II's putative ORF is based on a cDNA incomplete at the $5^{\prime}$ end, lacking a translation start site (Jones and Rubin, 1990).] We used two in vitro-generated mutants that had been designed by Jones and Rubin (1990) to eliminate full-length translation of the putative form I and form II proteins; these are called 1-STOP and 2-STOP, respectively.

Song analysis. Individual pairs of flies were placed in the recording chamber of an Insectavox (Gorczyca and Hall, 1987). The male's courtship song was recorded for $7.5-10 \mathrm{~min}$ on audio cassette tape and transferred to a Macintosh II computer's hard disk. The signal was converted from analog to digital at $2000 \mathrm{~Hz}$ with a MacAudios 11 digitizer. Pulse song locations were logged using LiFESONG software, developed in our laboratory (Bernstein et al., 1991), and the digitized song and filc of pulsc time locations were transferred to a VAX 8650 computer. Frequency spectra were computed using fast Fourier transforms. For a given pulse, the modal value of the primary frequency peak, which we call the intrapulse frequency (IPF), was obtained as in Fig. 3 (see also Wheeler et al., 1988). The number of cycles in a given pulse (CPP), which previously had been computed "by hand" (Kulkarni et al., 1988), were determined automatically by LIFESONG (Fig. 3).

Analyses of temporally based changes within a given train of song pulses were carried out by considering the CPP and IPF values as a function of position in the train (cf. Bernstein et al., 1991). Regression values were calculated for each of three individual flies, from trains containing $\geq 10$ pulses; song records chosen for this treatment contained $>300$ pulses. In the regressions, pulse position was the independent variable; CPP and IFP were the dependent ones. Before analysis of trains, pulse positions were normalized for train lengths; these are highly variable in Drosophila singing behavior (e.g., Kulkarni et al., 1988). Thus, CPP and IPF were each scored as functions of position on an $\mathrm{x}$-axis scale of $0.0-1.0$, which were made to correspond to the first and last pulses in a given train, respectively. [This differs from the previous method for obtaining dissonance-associated "polycyclicity slope" values in which each individual pulse was considered as one unit on the x-axis, with the result that the number of units varied with train length (Kulkarni et al., 1988).] Means \pm SEMs (the latter representing fly-to-fly variability within a genotype) were computed for the regression values.

The Kruskal-Wallis test, useful for testing ranked samples of $n>2$, was used to determine whether the genotypic groups came from identical or different populations, based on their means (Conover, 1980). $\chi^{2}$ approximations to the sampling distributions were obtained at $p=0.99$. For a given song character - temporally based changes in CPP or IPFmultiple comparisons between pairs of populations (again at $p=0.99$ ) were performed to determine whether groups were significantly different from mutant for that character (hence a "WT" decision for that genotype; see Results and Tables 3, 5), significantly different from wild-type ("MUT" in Tables 3,5), or different from neither (i.e., intermediate, "INT"). As a further assessment of a genotype's song phenotype, one of us (S.H.B.) examined (on the CRT screen) three song traces per genotype, with no knowledge of those genotypes, and classified each record as wild-type, mutant, or indeterminable. For this, four $10 \mathrm{sec}$ intervals of a given fly's song record, separated by about $100 \mathrm{sec}$, were viewed on the CRT screen. A "WT" decision for that song (see also Results and Tables 3,5) meant that all pulse trains observed looked like those produced by non $A^{+}$males (e.g., there were 1-3 CPP for essentially every pulse in the trains viewed), based on extensive prior examinations of dozens of normal song records. "MUT" meant that essentially all trains observed in that male's record contained dissonance-like pulses (with more than $3 \mathrm{CPP}$ ), this judgement being again backed up by previously examining the song traces from many mutant individuals. "Indeterminable" (see Table 3 notes) meant that the great majority of pulses examined in that male's song record were wild-typelike, but about three to five of them (from among the $40 \mathrm{sec}$ of signals scanned) were like those produced by the non $A^{\text {diss }}$ mutant (at least five or six cycles within such pulses).

The use of the tra mutation was necessary to allow assays of male courtship song behavior in diplo-X flies (see above). Temporal analyses of the IPF and CPP parameters for tra/tra pseudomales who carried no nonA-associated variants on their $\mathrm{X}$ chromosomes indicated that the pulse songs of these flies are not appreciably different from those of the various non $\mathrm{A}^{+}$-bearing controls (see below and Table 3 ).

Walking optomotor tests. This behavior was quantified using methods described by Greenspan et al. (1980) and Kulkami et al. (1988), with 
minor modifications. Individually stored flies, 3-8 d old, were darkadapted for $4 \mathrm{hr}$ in food vials and tested at room temperature for their turning behavior in a visual field. For this, an individual was placed under a $25-\mathrm{mm}$-diameter watch glass in the middle of a Plexiglas rotating drum (diameter, $15 \mathrm{~cm}$; height, $22.5 \mathrm{~cm}$ ), which had alternating black and white vertical stripes. Each black-white pair of stripes subtended $19^{\circ}$ of arc, and the drum was rotated at $20 \mathrm{rpm}$. White fluorescent light (Sylvania, FC12T10 CW RS) illuminated the center of the drum during the tests. Behavior was scored by counting the number of times the fly ran across a quadrant line in the same direction as the rotating stripes versus the number of times it ran in the opposite direction (cf. Greenspan et al., 1980). Four adults were tested per genotype. A given fly was tested in three successive trials, each consisting of a $1 \mathrm{~min}$ clockwise run followed by a $1 \mathrm{~min}$ run in the counterclockwise direction. A pcr-trial mean of the percentage of total lines crossed in the same direction as that of the moving stripes was calculated for each individual; the intra-fly variability was such that the standard deviations were usually in the range of $15-65 \%$ of the (individual fly score) means. The intra-fly averages were used to compute a mean (i.e., a mean of a mean), \pm SEM, for the four flies of that genetic constitution.

Electroretinograms. ERGs (cf. Pak and Grabowski, 1978; Heisenberg and Wolf, 1984) were recorded extracellularly from the adult eye as follows. Each fiy (3-8 d posteclosion) was anesthetized and immobilized on a glass slide with Elmer's glue. The cornea was penetrated slightly by a recording electrode (glass, $\sim 30 \mathrm{M} \Omega$ resistance) filled with $0.8 \%$ saline; a similar reference electrode was placed underneath the cuticle in the back of the head. The 3-8-d-old flies were then dark-adapted for $3 \mathrm{~min}$, and the retina was illuminated with a series of $3-\mathrm{sec}$ pulses of approximately $0.6 \mathrm{~W} / \mathrm{m}^{2}$ of incandescent light, separated by $30 \mathrm{sec}$ dark recovery periods. Light-evoked voltage changes were amplified with a Grass P18 amplifier and recorded on a Gould 2400 chart recorder. Intrafly means were calculated (based on the responses elicited by the separate light pulses) for the amplitudes of the light-on and light-off transient spikes, plus that of the maintained component (cf. Pak and Grabowski, 1978); the standard deviations for these per-fly values were usually 1$10 \%$ of the mean. A minimum of four animals expressing a given genotype was recorded, from which inter-fly means (of means), \pm SEM, were computed.

Kulkarni et al. (1988) reported that the non $A^{\text {diss }}$ hemizygous males and homozygous females have an ERG with a twofold reduction in the amplitude of its transient spikes, when compared with that of wildtype. We have subsequently found that this mutant's transient spikes were not only reduced but eliminated cntircly. The small transients seen previously in this particular mutant (Kulkarni et al., 1988) were an electrical artifact due to our shutter apparatus. Once this stimulus artifact was removed by moving the shutter farther away from the recording apparatus, both transients disappeared in recordings of non $A^{\text {diss }}$ males and of females heterozygous for non $A^{\text {diss }}$ and other nonA mutations. The corrected recording setup left the wild-type's on- and offtransients robust (see Results and Fig. 1).

Antibody generation. Mice were immunized with a protein produced by fusing the $3^{\prime}$ end of the Escherichia coli trpE gene to a Sal I fragment of the nonA cDNA type 23 (see Figs. 2, 4) in the pATH3 vector (Myers et al., 1987). This Sal I fragment corresponds to nucleotides 4434-7204 of the genomic DNA (cf. Jones and Rubin, 1990), including $864 \mathrm{nu}-$ cleotides of the open reading frame within cDNA 23 (Jones and Rubin, 1990). The procedure used to purify the fusion protcins was similar to methods previously described by Kleid et al. (1981) and Rio et al. (1986). Approximately $20 \mu \mathrm{g}$ of protein were injected subcutaneously into five female Balb-C mice, which were then boosted several times and bled at intervals of 1 month or more.

Immunoglobulins were precipitated from antisera with $45 \%$ ammonium sulfate, resuspended, and passed over a column of HB10I bacterial cell protein coupled to cyanogen bromide-activated sepharose (Pharmacia) to remove antibodies that reacted with general bacterial proteins. The eluate of this column was affinity purified by passage over a column of a $\beta$-galactosidase-NONA fusion polypeptide [produced by cloning nucleotides of the same Sal I genomic fragment as noted above into the vector pUR291 (Ruther and Müller-Hill, 1983)], coupled to $\mathrm{CNBr}$ activated sepharose. The column was washed with phosphate-buffered saline (PBS; pII 7.2), then PBS plus $0.5 \mathrm{M} \mathrm{NaCl}$, and the antibody was eluted from the column with glycine $\mathrm{HCl}(\mathrm{pH} 2.5)$. Fractions were collected, neutralized on ice with $1.0 \mathrm{M}$ Tris base, and tested for immunoreactivity with the NONA-TRPE fusion protein (using an ELISA, as in Hudson and Hay, 1980). Antibody-containing fractions were com- bined, BSA to $1 \mathrm{mg} / \mathrm{ml}$ was added, and dialysis of this material against an excess of $200 \mathrm{vol}$ of PBS was carried out overnight at $4^{\circ} \mathrm{C}$ with several changes of the dialysis buffer.

Immunochemistry. For Western analyses, 20 fly heads (per genotype) were homogenized in $80 \mu \mathrm{l}$ of Laemmli buffer ( $2 \%$ SDS, $10 \%$ glycerol, $100 \mathrm{~mm}$ dithiothreitol, $60 \mathrm{~mm}$ Tris, $\mathrm{pH} 6.8$ ), heated at $100^{\circ} \mathrm{C}$ for $5 \mathrm{~min}$, and centrifuged to remove debris; $20 \mu \mathrm{l}$ of each homogenate were run on an $8 \%$ polyacrylamide-SDS denaturing gel and transferred to nitrocellulose (Schleicher and Schuell), using the wet transfer method. The filters were preincubated with PBS plus $2 \%$ instant nonfat milk for 30 min at room temperature and incubated with the anti-NONA antibody at a dilution of 1:200 for $1 \mathrm{hr}$. They were then washed three times for 10 min in PBS plus 10\% serum (Cappel) and 0.5\% Tween-20 (Sigma). The blots were incubated in goat anti-mouse IgG conjugated to HRP (Sigma) at a 1:200 dilution for $1 \mathrm{hr}$ in PBS plus 10\% serum and then washed as above; the reaction products were visualized by adding the substrate $0.5 \mathrm{mg} / \mathrm{ml}$ 3,3-diaminoazobenzadine (DAB; Sigma) in PBS plus $0.003 \% \mathrm{H}_{2} \mathrm{O}_{2}$.

Immunocytochemistry. Tissues of animals from different developmental stages and of adults were stained at either a 1:10,000 dilution of affinity-purified antibody for whole-mount embryos or a 1:4000 dilution for sectioned material. Embryos were dechorionated in $50 \%$ bleach for $3 \mathrm{~min}$, rinsed in $0.2 \%$ saline, and fixed in $4 \%$ paraformaldehydesaturated heptane for $10 \mathrm{~min}$; their vitelline membranes were removed by shaking vigorously in a mixture of $50 \%$ heptane and methanol. They were then washed in PBT [PBS, $0.2 \%$ BSA (Sigma) and $0.1 \%$ Triton $\mathrm{X}-100$ (Boehringer Mannheim)], preincubated in PBT plus $3 \%$ normal goat serum (Cappel) for $1 \mathrm{hr}$ at room temperature on a rotator, and incubated overnight at $4^{\circ} \mathrm{C}$ with primary antibody. Larvac, pupac, and adults were embedded (as whole animals) and frozen in OCT medium (Tissue Tek); sectioned at a thickness of $10 \mu \mathrm{m}$ using an S.L.E.E. cryostat; fixed in 4\% paraformaldehyde in PBS (pH 7.2); rinsed in PBS; preincubated in PBS plus $0.03 \%$ Triton X-100, $0.1 \%$ BSA, and $3 \%$ normal goat serum; and incubated overnight at $4^{\circ} \mathrm{C}$ with primary antibody. The embryos or sections were incubated with the secondary antibody, antimouse IgG conjugated to HRP, for approximately $2 \mathrm{hr}$ at room temperature, and the reaction products were visualized with the substrate $\mathrm{DAB}$ plus $0.03 \%$ peroxide added. Slides were rinsed in PBS and allowed to air dry for about $5 \mathrm{~min}$, coated with Crystal Mount (Biomeda), baked for $15 \mathrm{~min}$ at $80^{\circ} \mathrm{C}$, and finally mounted with DPX (Fluka). The specimens were viewed with Nomarski optics with a Zeiss Axiophot microscope.

Sequence analysis. Comparisons and manipulations of nonA's informational content (as reported in Jones and Rubin, 1990) were carried out using the Genetics Computer Group software (Devereux et al., 1984; Devereux, 1989), from the University of Wisconsin Biotechnology Center. Homology searches were carried out with the FASTA program (using the method of Pearson and Lipman, 1988), and the BASIC LOCAL ALIGNMENT SEARCH TOOL (Altschul et al., 1990) program, to scan the NBRF and GenEMBL nucleic acid and predicted protein sequence data bases. The sequences were aligned with the aid of the "dynamic" algorithm of Smith and Smith (1990).

\section{Results}

\section{Cytogenetic mapping of the two phenotypic defects exhibited} by diss

Behavioral and physiological tests of progeny from crosses involving non $A^{\text {diss }}$ and other genetic variants at or near this $X$-chromosomal gene localized the mutation to the "proximal $14 \mathrm{~B}$ " region of that chromosome. This genetic analysis also achieved a narrower localization for non $A^{\text {diss }}$ than previously reported (Kulkarni et al., 1988). The results presented here (Table 2) are in agreement with the cytogenetic localization of $n o n A^{H 2}$ by Jones and Rubin (1990). These investigators, as well as Besser et al. (1990), also localized nonA by chromosomal in situ hybridization, concluding that it maps within 14C1-2. We now show that $T(1 ; 4)+D f(1) 81 k 21 e$ (cf. Table 1) covered the effects of non $A^{\text {diss }}$ in ERG and optomotor tests (Tables 2, 3). The duplication in $T(1 ; 2) r^{+75 c}$ (cf. Table 1) was reported to cover the effects of non $A^{\text {diss }}$ or $n o n A^{H 2}$ in visual response tests (Kulkarni et al., 1988; Jones and Rubin, 1990); this result has been con- 
Table 2. Mapping and complementation analysis of visual defects

\begin{tabular}{|c|c|c|c|c|}
\hline \multirow[b]{2}{*}{ Genotype } & \multicolumn{3}{|c|}{ ERG component amplitudes } & \multirow{2}{*}{$\begin{array}{l}\text { Optomotor } \\
\text { score }\end{array}$} \\
\hline & On & Sustained & Off & \\
\hline \multicolumn{5}{|l|}{ Normal controls } \\
\hline$+/ Y$ & $4.6 \pm 0.7$ & $12.2 \pm 0.9$ & $8.3 \pm 0.8$ & $96 \pm 2$ \\
\hline non $A^{d i s s} /$ non $A^{+}$ & $4.1 \pm 0.2$ & $12.4 \pm 0.8$ & $4.7 \pm 0.6$ & $84 \pm 3$ \\
\hline$g^{2}$ sd non $A^{d i s s} f /$ non $A^{+}$ & $1.8 \pm 0.4$ & $8.1 \pm 0.8$ & $2.7 \pm 0.5$ & $88 \pm 3$ \\
\hline$D f(1) E 150 /$ nond $^{+}$ & $4.1 \pm 0.2$ & $4.9 \pm 0.5$ & $2.8 \pm 0.5$ & $88 \pm 3$ \\
\hline \multicolumn{5}{|l|}{ Chromosome aberrations } \\
\hline$D f(1) E 150 /$ non $A^{d i s s}$ & $0.0 \pm 0.0$ & $16.6 \pm 2.5$ & $0.0 \pm 0.0$ & $45 \pm 2$ \\
\hline nond $A^{d i s s} / Y ; T(1 ; 2) r^{+7 s c}$ & $4.1 \pm 0.2$ & $10.7 \pm 0.7$ & $4.6 \pm 0.4$ & $88 \pm 3$ \\
\hline nonA $A^{d i s s} f / Y ; D f(1) 81 k 21 e$ & $5.9 \pm 0.4$ & $11.3 \pm 1.0$ & $5.4 \pm 1.2$ & $89 \pm 3$ \\
\hline \multicolumn{5}{|l|}{ NonA mutants } \\
\hline$n o n A^{H 2} f / Y$ & $0.0 \pm 0.0$ & $7.8 \pm 0.8$ & $0.0 \pm 0.0$ & $53 \pm 3$ \\
\hline$n o n A^{P 14} / Y$ & $1.2 \pm 0.2$ & $9.3 \pm 0.5$ & $0.0 \pm 0.0$ & $59 \pm 9$ \\
\hline$n o n A^{P 49} / Y$ & $0.0 \pm 0.0$ & $8.1 \pm 1.2$ & $0.0 \pm 0.0$ & $50 \pm 3$ \\
\hline$n o n A^{P \sigma o / Y}$ & $0.0 \pm 0.0$ & $7.1 \pm 0.9$ & $0.0 \pm 0.0$ & $49 \pm 3$ \\
\hline nonA $A^{\text {diss }} f / Y$ & $0.0 \pm 0.0$ & $9.5 \pm 0.7$ & $0.0 \pm 0.0$ & $50 \pm 3$ \\
\hline \multicolumn{5}{|l|}{ Allelic complementation } \\
\hline$n o n A^{H 2} f / g^{2}$ sd non $A^{d i s s} f$ & $0.0+0.0$ & $7.3 \pm 0.4$ & $0.0 \pm 0.0$ & $53 \pm 3$ \\
\hline non $A^{P 14} /$ non $A^{\text {diss }} f$ & $0.0 \pm 0.0$ & $14.6 \pm 1.2$ & $0.0 \pm 0.0$ & $52 \pm 2$ \\
\hline nonA $A^{P 49} /$ nonA $A^{\text {diss }} f$ & $0.0 \pm 0.0$ & $13.4 \pm 0.5$ & $0.0 \pm 0.0$ & $53 \pm 1$ \\
\hline non $A^{P 60} /$ non $A^{d i s s} f$ & $0.0 \pm 0.0$ & $13.3 \pm 0.9$ & $0.0 \pm 0.0$ & $49 \pm 2$ \\
\hline
\end{tabular}

nonA $A^{\text {diss }}$-bearing flies that also carried a given chromosome aberration had their ERGs recorded and optomotor responses assessed; the results are in the second section of the table. Complementation tests (last section) were also performed, in which non $A^{\text {diss }}$ was heterozygous with a given non $A$ mutation that, by itself, leads only to visual defects (as shown in the third section). Controls for these complementation tests are in the first section of the table. The chromosome aberrations in the leftmost column are described in Table 1 . In addition, $F M 7 a$ (a $B$-bearing $\mathrm{X}$ chromosomal balancer) was the source of non $A^{+}$in the normal controls tested for ERGs; for the optomotor tests, non $A^{+}$was a Canton-S-derived X. nonA $A^{\text {diss }}$ was linked to one or more X chromosome markers in each case $\left(g^{2}, s d\right.$, and/or forked). ERG values and optomotor scores were obtained as described in Materials and Methods. All the X-chromosomal heterozygous types (within all sections but the third one) were homozygous for the third-chromosomal tra mutation (compare Table 3); controls (not shown) showed that $t r a$ had no significant effects on the flies' visually mediated responses, in a non $A^{+}$genetic background. The rather variable amplitudes of the ERG maintaincd components are mostly the consequence of varying placements of recording electrodes and are unlikely to have biological (e.g., genotypic) significance.

firmed (Table 3), using the new strategy for song analysis (see below). Therefore, the genetic factor causing non $A^{\text {diss's visually }}$ impaired phenotype maps within 14B13-18 (see Table 1 notes), according to the breakpoint positions of the chromosome aberrations just noted, which are the ones closest to the mutation (cf. Kulkarni et al., 1988; Jones and Rubin, 1990). This is a slightly more distal region than that concluded from in situ hybridizations, though there is probably no real discrepancy (see Table 1 notes). In any event, the molecularly determined distance between these two closest breakpoints (in the $81 \mathrm{k} 21 \mathrm{e}$ deletion and in the $r^{+75 c}$ duplication) is $20 \mathrm{~kb}$ (Jones and Rubin, 1990).

Mapping the courtship song abnormalities caused by non $A^{\text {diss }}$ involved determinations of a tendency for the numbers of CPP to increase in "trains" of such song pulses (cf. Kulkarni et al., 1988). In addition, a newly revealed element of this mutant's singing behavior was analyzed in flies expressing the various $n o n A$-associated genotypes. This involves the fact that $n o n A^{\text {diss }}$ pulses exhibit markedly higher "carrier" IPFs as a train proceeds, based on Fourier and regression analyses of these song signals and how they tend to change over the course of a typical bout of the mutant's singing. In contrast, the IPFs of normal pulse trains tend to decrease for later pulses in a given song bout (Table 3).

Decisions on the CPP and IPF phenotype influenced by a given genotype in the cytogenetic experiments (and others; see below) were made by statistical analyses of digitized song signals (see Materials and Methods); these computer-based decisions about the song records were augmented by others, stemming from blind observations of such data, with regard to the CPP "parameter" (see Materials and Methods). In this way, the two duplications noted above essentially covered the effects of non $A^{\text {uis }}$, though not unambiguously so (Table 3 ). Tentatively, however, the genetic etiology of the song and visual defects caused by this mutation map to the same $20 \mathrm{~kb}$ region of the $\mathrm{X}$ chromosome.

All of the existing nonA alleles are recessive (Pak, 1975; Kulkarni et al., 1988), and when hemizygous in a male or homozygous in diplo-X flies, all but one, non $A^{P 14}$, caused a similar lack of ERG transient spikes (Table 2). non $A^{P 14}$ showed an appreciable, albeit significantly reduced, light-on transient, which was followed by no detectable light-off transient (Table 2). non $A^{\text {diss }}$, when heterozygous with any of the visual-only nonAs in a tra genetic background, also led to an absence of the onand off-transient spikes, not a mere reduction in these amplitudes, as previously reported (Kulkarni et al., 1988; see Materials and Methods). non $A^{\text {diss }} / D f(1) E 150$ (the latter variant being a non $A^{-}$deletion; Table 1) led to a similar phenotype (Fig. 1, Table 2).

Although the pattern of interallelic complementation is 
Table 3. Courtship songs influenced by diss and nearby genetic variants

\begin{tabular}{|c|c|c|c|c|c|}
\hline \multirow[b]{2}{*}{ Genotype } & \multirow[b]{2}{*}{$(N)$} & \multirow[b]{2}{*}{ CPP score } & \multirow[b]{2}{*}{ IPF score } & \multicolumn{2}{|l|}{ Phenotype } \\
\hline & & & & Computer & Observer \\
\hline \multicolumn{6}{|l|}{ Normal controls } \\
\hline$+/ Y$ & $(13)$ & $0.36 \pm 0.04$ & $-19.32 \pm 7.18$ & (WT) & (WT) \\
\hline$+/+$ & $(10)$ & $0.25 \pm 0.80$ & $-5.34 \pm 2.25$ & WT & \\
\hline non $A^{d i s s} f /$ non $^{+}$ & & $0.33 \pm 0.24$ & $-13.29 \pm 7.80$ & WT & \\
\hline$g^{2} s d$ non $A^{d i s s} f /$ non $^{+}$ & & $0.21 \pm 0.07$ & $-4.64 \pm 8.99$ & WT & \\
\hline$D /(1) E 150 /$ nonA $A^{\prime}$ & & $-0.07 \pm 0.04$ & $-4.84 \pm 8.48$ & WT & \\
\hline \multicolumn{6}{|l|}{ Chromosome aberrations } \\
\hline non $A^{\text {diss }} f / D f(1) E 150$ & & $1.94 \pm 0.31$ & $43.70 \pm 12.74$ & MUT & MUT \\
\hline non $A^{\text {diss }} f ; T(1 ; 2) r^{+75 c}$ & & $-0.01 \pm 0.16$ & $7.54 \pm 6.05$ & WT/INT & WT \\
\hline nonA $A^{\text {diss }} f ; D f(1) 81 \mathrm{k} 21 e$ & & $0.43 \pm 0.23$ & $6.21 \pm 9.59$ & WT/INT & INT \\
\hline non $A^{P 14} f / D f(1) E 150$ & & $0.71 \pm 0.31$ & $12.51 \pm 12.64$ & WT/INT & WT \\
\hline \multicolumn{6}{|l|}{ non $A^{\text {diss }}$ controls } \\
\hline non $A^{\text {diss }} f / Y$ & $(10)$ & $2.43 \pm 0.33$ & $45.95 \pm 13.28$ & (MUT) & (MUT) \\
\hline non $A^{d i s s} f / n o n A^{d i s s} f$ & (7) & $1.79 \pm 0.41$ & $43.35 \pm 8.07$ & MUT & \\
\hline \multicolumn{6}{|l|}{ Visual nonA mutants } \\
\hline non $A^{H 2} / Y$ & & $0.32 \pm 0.18$ & $-22.82 \pm 17.09$ & WT & WT \\
\hline$n o n A^{P 14} / Y$ & & $0.01 \pm 0.09$ & $-12.53 \pm 4.78$ & WT & WT \\
\hline$n o n A^{P 49} / Y$ & & $-0.01 \pm 0.03$ & $-28.38 \pm 14.41$ & WT & WT \\
\hline$n O n A^{P 60} / Y$ & & $-0.17 \pm 0.13$ & $-21.70 \pm 10.30$ & WT & WT \\
\hline \multicolumn{6}{|l|}{ Allelic complementation } \\
\hline non $A^{H 2} f / g^{2} s d$ non $A^{d i s s} f$ & & $0.30 \pm 0.05$ & $-2.37 \pm 6.87$ & WT & WT \\
\hline non $A^{P 14} /$ non $A^{d / s s} f$ & & $0.80 \pm 0.22$ & $3.85 \pm 0.86$ & INT/WT & INT \\
\hline non $A^{P 49} /$ non $A^{d i s s} f$ & & $0.19 \pm 0.06$ & $-7.03 \pm 11.18$ & WT & WT \\
\hline nond $A^{P 60} /$ nond diss $f$ & & $0.44 \pm 0.19$ & $-12.41 \pm 22.84$ & WT & INT \\
\hline
\end{tabular}

Chromosome aberration-aided mapping and complementation tests were performed on males or (tra/tra) pseudomales carrying non $A^{\text {diss }}$ and/or other nonA mutations. The four genotypic groups appearing in Table 2 are represented here as well, plus a new section (non $A^{\text {diss }}$ controls) involving diss mutants. For the normal controls, non $A^{+}$was provided by an $F M 7 a$ balancer (compare Table 2). The number of flies tested was three per genotype, unless otherwise indicated $(N)$. Song "scores" are given as the regression (slope) values for two parameters, reflecting changing patterns of CPP and IPF over the course of pulse trains (song bouts). Complementation data for courtship songs of non $A$ and other genetic variants were analyzed by pairwise comparisons of ranked test groups (see Materials and Methods) against a wild-type (CantonS) control (Normal controls, $+/ Y$ ) and a mutant (non $A^{\text {diss }}$ ) control (songs from the 10 males in non $A^{\text {diss }}$ controls, non $A^{\text {diss }}$ $f / Y)$. For the two columns listing the phenotypic decisions, WT indicates wild-type-like and MUT indicates diss-mutantlike (the parenthetical indications of these two symbols designate the by-definition normal and mutant values, or songtrace appearances from the blind observations; see below). For the numerically and statistically based forms of these decisions (Computer phenotype), WT indicates that both the CPP and IPF regression scores were indistinguishable from normal, with MUT meaning that both scores were indistinguishable from the (straight) song mutant values; WT/INT indicates that the average CPP score for this genotypic group was statistically indistinguishable from normal, but the IPF score was intermediate, that is, between, and not statistically different from, either wild-type or mutant averages; INT/WT indicates that the CPP score was intermediate in this manner, with the IPF score being statistically indistinguishable from normal. For the decisions based on viewing the song traces "blind to genotype" (Observer phenotype); WT indicates that all three of the traces examined for that genotype looked clearly normal; MUT indicates either that they all looked clearly diss-like or that two appeared to be mutant with the other "indeterminable" (see Materials and Methods), or (rarely) that one trace was mutant-like with the other two being indeterminable; INT means that one or two of the traces (for the genotype in question) were wild-type-like, with the remaining two or one being indeterminable. Note that the blind observer found no genotypes to contain all three traces of an indeterminable type, nor were any groups of three ever judged to contain a mixture of wild-type- and mutant-like traces; thus, the worst cases of ambiguity were mixtures of normal/indeterminable or mutant/indeterminable.

straightforward for the visual phenotype, it is more complex for courtship song. Two of the four visual-only mutants-non $A^{H 2}$ and $n o n A^{P 49}$-clearly complemented non $A^{\text {diss }}$ for the song phenotype (Table 3). Two of these complementation tests, involving the various non $A$ visual mutations that resulted in normal singing when hemizygous in males (Table 3 ), led to song phenotypes with marginally mutant characteristics. This was more pronounced from the analyses performed, and blind observations made, on the non $A^{\text {diss }} /$ non $A^{P 14}$ songs (Table 3). non $A^{P 14}$ also exhibited decreased expression of the gene product (see below).

$n o n A^{\text {diss }}$ was not abnormal at this level of biochemical observation (see below), but it exhibits the most widespread behavioral defects. For its courtship abnormality, this mutation led to similar regression values in the songs of hemizygous mutant males and in flies heterozygous for the diss allele and a deletion of the locus (Table 3), yet the severity of the phenotype caused by one dose of non $A^{\text {diss }}$ in diplo-X flies was not fully revealed by the numerical analysis. First, consider the example of a song bout, with its extremely polycyclic pulses, recorded from a (diplo-X; tra) pscudomalc of this type shown (Fig. 1B). Moreover, two of the three such pseudomales analyzed contained wildly polycyclic pulses in their songs, with 4 and 22 individual trains containing between 12 and 100 cycles; the third pseudomale generated no such pulses. [Flies of this genotype were difficult to obtain for further observations, because of low viability (see also Kulkarni et al., 1988).] In contrast, the largest numbers of 
Table 4. Visual phenotypes of diss transformants

\begin{tabular}{|c|c|c|c|c|}
\hline \multirow[b]{2}{*}{ Genotype } & \multicolumn{3}{|c|}{ ERG component amplitudes } & \multirow{2}{*}{$\begin{array}{l}\text { Optomotor } \\
\text { score }\end{array}$} \\
\hline & On & Sustained & Off & \\
\hline \multicolumn{5}{|l|}{ Genomic constructs } \\
\hline nonA $A^{\text {diss }} f / Y ; \mathrm{R} 11 \mathrm{~A} /+$ & $3.7 \pm 0.3$ & $4.9 \pm 0.3$ & $2.7 \pm 0.4$ & $96 \pm 1$ \\
\hline nonA diss $f / Y ; \mathrm{R} 11 \mathrm{~B} /+$ & $3.2 \pm 0.5$ & $6.4 \pm 0.4$ & $5.2 \pm 0.6$ & $99 \pm 1$ \\
\hline non $A^{\text {diss }} f / Y ; \mathrm{XS} 16 \mathrm{~A} /+$ & $0.0 \pm 0.0$ & $8.3 \pm 0.5$ & $0.0 \pm 0.0$ & $88 \pm 0$ \\
\hline nonA $A^{d i s s} f / Y ; \mathrm{XS} 16 \mathrm{~B} /+$ & $5.5 \pm 0.6$ & $8.3 \pm 0.8$ & $7.5 \pm 0.7$ & $95 \pm 2$ \\
\hline \multicolumn{5}{|l|}{ in vitro mutagenized constructs } \\
\hline nonA $A^{d i s s} f / Y ; 1-S T O P \mathrm{~A} /+$ & $0.0 \pm 0.0$ & $13.6 \pm 0.7$ & $0.0 \pm 0.0$ & $55 \pm 3$ \\
\hline nonA $A^{\text {diss }} f / Y ; 1-\mathrm{STOP} \mathrm{B} /+$ & $0.0 \pm 0.0$ & $8.4 \pm 1.0$ & $0.0 \pm 0.0$ & $51 \pm 4$ \\
\hline nonA $A^{\text {diss }} f / Y ; 2-\mathrm{STOP} \mathrm{A} /+$ & $3.6 \pm 0.3$ & $8.4 \pm 0.7$ & $6.5 \pm 0.5$ & $95 \pm 3$ \\
\hline nond $A^{\text {diss }} f / Y ; 2$-STOP B/+ & $2.5 \pm 0.1$ & $6.4 \pm 0.2$ & $1.2 \pm 0.3$ & $98 \pm 0$ \\
\hline
\end{tabular}

Transgenics involving transduced nonA-locus ( $r y^{+}$-linked) DNA (as depicted in Fig. 2) and a $n o n A^{d \omega s} / Y$; $r y^{506}$ genetic background, were tested for ERGs and optomotor behavior. R11 and the XS16 designate genomic fragments that were previously shown to rescue ERG phenotypes in a non $A^{\prime \prime 2}$ mutant background (Jones and Rubin, 1990). Note that the only difference between XS16 lines A and B is the opposite orientation of the restriction fragments inserts relative to the $r y^{+}$marker in the plasmid used as the "transformation vehicle" (cf. Jones and Rubin, 1990). S12 is a DNA fragment derived from a more distal genomic region (Fig. 2) than the sourccs of the R and XS fragments noted above. The in vitro--mutated constructs 1-STOP and 2-STOP are variants of R11 that each have stop codons, which were placed near the unique 35 and 33 amino acid termini of the putative proteins form I and II (Fig. 2), respectively. See Materials and Methods for procedures and computational strategies concerning the visual response tests and analyses of data stemming from them.

cycles for a given pulse in the songs of all the 21 hemizygous nonA ${ }^{\text {diss }}(\mathrm{XY})$ males recorded for this study (see Tables 3,5 ), after maximizing the mutant phenotype by outcrossing (see Materials and Methods), was 12.

Behavioral mutants in $D$. melanogaster, which are necessarily viable by virtue of their strategy of isolation, sometimes turn out to be mutated at essential genetic loci (e.g., Homyk et al., 1985; Lipshitz and Kankel, 1985; Watanabe and Kankel, 1990). If this were the case for non $A^{\text {diss }}$, certain of the independently induced lethal mutations mapping near this locus might fail to complement the song-visual mutation. In fact, the other courtship song mutation in this species, cacophony (cac), is not complemented in heterozygotes involving several allelic lethal mutations mapping to the cac locus (Kulkarni and Hall, 1987), yet the three lethals mapping nearest to non $A^{\text {diss }}$ led to normal singing and optomotor behavior (data not shown), in tests of the pertinent heterozygous diplo-X flies (see Materials and Methods). Such results are in agreement with those involving ERGs of the non $A^{H^{2}}$ allele, in combination with two of these lethal mutations (Jones and Rubin, 1990). The two sets of findings indicate that non $A$ has not yet been mutated to lethality, or that it cannot cause such a phenotype when it has suffered a loss-offunction mutation (see Discussion).

\section{Transformation rescue of courtship and visual defects}

Genomic DNA has been cloned from the proximal 14B/distal $14 \mathrm{C}$ region of the $\mathrm{X}$ chromosome (Besser et al., 1990; Jones and Rubin, 1990; Surdej et al., 1990). Phenotypic rescue of non $A^{\text {diss's }}$ s visually mutant phenotypes was readily observed (Table 4) in germline transgenics that had been previously generated by Jones and Rubin (1990). These transformed flies carry either of two constructs: an $11 \mathrm{~kb}$ Eco RI or a $16 \mathrm{~kb}$ Xba I-Sac I fragment of genomic DNA, which overlap by $9 \mathrm{~kb}$ (Fig. 2). Three of these four lines containing the genomic DNA inserts in a non $A^{\text {diss }}$ genetic background displayed robust rescue of visual defects, giving wild-type ERG transients and optomotor scores (Table 4). This is in agreement with the results of Jones and
Rubin (1990), who demonstrated rescue of the $n o n A^{H 2}$ allele by both genomic fragment types. In one line (XS16A) the ERG transients' absences were not rescued, although the optomotor score was 88 , closer to wild-type values (typically $\sim 95$ ) than the mutant score (typically 50-60). Given that the other strain transformed with the Xba I-Sac I fragment gave a normal ERG and optomotor response, the incomplete rescue in XS16A is likely to be a position effect of the insert location (see Discussion).

For the courtship song phenotypes of transgenic males, the two genomic fragment types noted above gave clear rescue of the abnormal pulses in terms of the CPP character, in a nond diss background (Table 5). The carrier frequency (IPF) regression scores for these four genotypes were, however, classified as intermediate or even mutant-like (with regard to fragment type XS16, line A). Nevertheless, the overall pattern of results (see Table 5, Phenotype) indicates this DNA also contains appreciable biological activity in terms of ameliorating non $A^{\text {diss's }}$ effects on courtship song. Moreover, the control strains (S12A and $\mathrm{S} 12 \mathrm{~B}$ ), which had been transformed with a genomic fragment mapping more distally on the chromosome (Fig. 2), exhibited no rescue of the mutant song phenotypes (Table 5). This is consistent with the ERG analysis of these two transgenic lines (Jones and Rubin, 1990). In the main, these results (see Table 5 , Mutant controls and Genomic constructs) strengthen the conclusion that the diss mutation is a nonA allele.

Two deliberately altered constructs of the (otherwise) rescuing $11 \mathrm{~kb}$ genomic fragment were assayed for their effects on behavioral phenotypes in a non $A^{\text {diss }}$ genetic background. 1-STOP and 2-STOP refer to variants with translation-terminating codons inserted in the DNA near the mRNA splice sites that would produce the two different polypeptides encoded by transcripts corresponding to the two cDNA types depicted in Figure 2. 1-STOP, designed to eliminate only the putative form I protein, failed to rescue the ERG defect induced by the visual-only mutation $n o n A^{H 2}$, whereas 2-STOP, which would produce a normal form I but no form II, restored this mutant's missing on- and off-transients (Jones and Rubin, 1990). In principle, the two 


\begin{tabular}{|c|c|c|c|c|c|}
\hline \multirow[b]{2}{*}{ Genotype } & \multirow[b]{2}{*}{$(N)$} & \multirow[b]{2}{*}{ CPP score } & \multirow[b]{2}{*}{ IPF score } & \multicolumn{2}{|l|}{ Phenotype } \\
\hline & & & & Computer & $\begin{array}{l}\text { Ob- } \\
\text { server }\end{array}$ \\
\hline \multicolumn{6}{|l|}{ Mutant controls } \\
\hline nond $A^{\text {diss }} f / Y$ & (4) & $2.90 \pm 1.01$ & $86.44 \pm 51.19$ & (MUT) & (MUT) \\
\hline$n o n A^{d i s s} f / Y ; \mathrm{S} 12 \mathrm{~A} /+$ & & $3.16 \pm 0.62$ & $74.23 \pm 12.26$ & MUT & MUT \\
\hline non $A^{\text {diss }} f / Y ; \mathrm{S} 12 \mathrm{~B} /+$ & & $4.30 \pm 0.19$ & $132.01 \pm 3.65$ & MUT & MUT \\
\hline \multicolumn{6}{|l|}{ Genomic constructs } \\
\hline non $A^{\text {diss }} f / Y ; \mathbf{R} 1 \mathbf{1 A} /+$ & & $-0.29 \pm 0.13$ & $5.93 \pm 1.79$ & WT/INT & WT \\
\hline non $A^{\text {diss }} f / Y ; \mathrm{R} 11 \mathrm{~B} /+$ & & $0.12 \pm 0.13$ & $7.79 \pm 3.74$ & WT/INT & WT \\
\hline non $A^{d i s s} f / Y ; \mathrm{XS} 16 \mathrm{~A} /+$ & & $0.75 \pm 0.22$ & $23.19 \pm 10.72$ & WT/MUT & WT \\
\hline $\begin{array}{l}\text { non } A^{\text {diss }} f / Y ; \mathrm{XS} 16 \mathrm{~B} /+ \\
\text { in vitro mutagenized constru }\end{array}$ & & $0.05 \pm 0.12$ & $7.84 \pm 4.96$ & WT/INT & WT \\
\hline non $A^{d i s s} f / Y ; 1-S T O P \mathrm{~A}+$ & & $0.82 \pm 0.21$ & $38.81 \pm 16.17$ & INT/MUT & INT \\
\hline$n o n A^{d i s s} f / Y ; 1-\mathrm{STOP} \mathrm{B} /+$ & & $2.71 \pm 0.92$ & $66.18 \pm 22.29$ & MUT & MUT \\
\hline non $A^{d i s s} f / Y ; 2-\mathrm{STOP} \mathrm{A} /+$ & & $0.23 \pm 0.15$ & $5.52 \pm 4.95$ & WT/INT & WT \\
\hline nond diss $f / Y ; 2-\mathrm{STOP} \mathrm{B} /+$ & & $0.10 \pm 0.03$ & $2.98 \pm 1.72$ & WT & WT \\
\hline
\end{tabular}

The same kinds of $n o n A^{\text {diss }}$-bearing transgenics as in Table 5, plus an additional type involving the "non-visual-rescuing" DNA fragment S12 (see Fig. 2), had their songs recorded and analyzed as in Table 3 . The phenotypic classifications based on regression analyses (Computer phenotype) were as described in Table 3 notes. The (by-definition) wild-type values (WT) in that column were used for the present statistics. A new phenotypic category appears here in the Computer phenotype (WT/MUT) and indicates that the CPP regression score was indistinguishable from that of wild-type, with the IPF score being not significantly different from that of the diss mutant. The decisions made from viewings of song traces by a "blind" investigator (Observer phenotype) were categorized as described in Table 3 notes.

different proteins (if they are real) could be generated in widely separate tissues, with their respective absences affecting visual and song phenotypes differently. However, no evidence in favor of such a model was obtained from tests of transformants involving $n o n A^{\text {diss }}$. 2-STOP robustly rescued ERG transient, optomotor, and the CPP-associated courtship song defects of this mutant, whereas 1-STOP failed fully to rescue either the visual functions or the song mutant phenotype (Tables 4,5 ). Thus, we suggest that the inferred non $A$ form I protein encoded by cDNA 23 is sufficient to supply all biological functions missing in the non $A^{\text {diss }}$ mutant. The putative form II protein does not as yet provide a known function associated with this genetic locus.

\section{RNA and protein analysis}

The mRNAs detected from the non $A$ genomic region appear to be similar in size and abundance in the wild-type (Canton-S) and non $A^{\text {diss }}$. Using a $0.6 \mathrm{~kb}$ Pst I-Sal I genomic fragment (cloned from non $A$ ) as a probe, transcripts of approximately 4.0, 3.0, and $2.8 \mathrm{~kb}$ were previously detected on Northern blots in the heads of wild-type flies (Jones and Rubin, 1990). We observed the same-sized transcripts in RNA extracted separately from the heads and bodies of males and females expressing either non $A^{\text {diss }}$ or the normal allele (data not shown). This $0.6 \mathrm{~kb}$ fragment also detected, for either genotype, smaller RNA species not seen with other probes from the nonA region; the $0.6 \mathrm{~kb}$ probe is believed to cross-react with nonA "repeated sequences," that is, those present in other genes and transcripts (see Jones and Rubin, 1990).

Figure $4 A$ indicates the portion of cDNA 23 that was fused to the $5^{\prime}$ end of the $E$. coli trpE gene to produce the fusion protein used to immunize mice. Western blot experiments showed that the resulting polyclonal antibody binds to an 80 kDa protein present in Drosophila head extracts (Fig. 4B). No immunoreactivity was observed in the flow-through from the affinity column, from which the NONA antibody had been depleted (see Materials and Methods). Preimmune serum was not available as a further control.

A Western blot involving head extracts from male and femalc Canton-S (wild-type) and five non $A$ mutant alleles indicated that all produce a full-length protein. non $A^{P I 4}$ extracts, however, showed appreciable decrements in the levels of the protein in both sexes (Fig. 4B).

Immunoprecipitation experiments were performed using labeled NONA protein. An RNA copy of the ORF corresponding to cDNA 23 was generated (via the "SP6" system), and this product was in vitro translated using ${ }^{35} \mathrm{~S}$-methionine. The antiNONA antibody was then used to immunoprecipitate radiolabeled polypeptide. This led to antibody-mediated detection, on gels, of an $80 \mathrm{kDa}$ protein and $44 \mathrm{kDa}$ band (data not shown); the latter was also occasionally observed on the Western blots and could be a degradation product.

\section{Spatial expression of nonA-encoded products}

In situ hybridizations to whole-mounts of embryos were performed with digoxygenin-labeled antisense RNA probe, corresponding to a 1050 nucleotide Sal I fragment from cDNA 23 (which does not contain sequence motifs that are believed to be cross-reactive with RNAs encoded by genes other than nonA). The whole-mounted preparations revealed a ubiquitous distribution of that gene's transcript throughout the embryo (data not shown), a result that is consistent with the NONA protein localization, whose description follows.

A developmental profile of immunohistochemically determined reactivity to the NONA antigen(s) showed this material to be present ubiquitously in the developing oocyte and the embryonic, larval, pupal, and adult stages (Fig. 5). Although the NONA protein appeared to be nuclear in the maturing oocyte, in the developing zygote this protein seemed to be localized to the cytoplasm until the cellular blastoderm stage (cf. Frasch and 


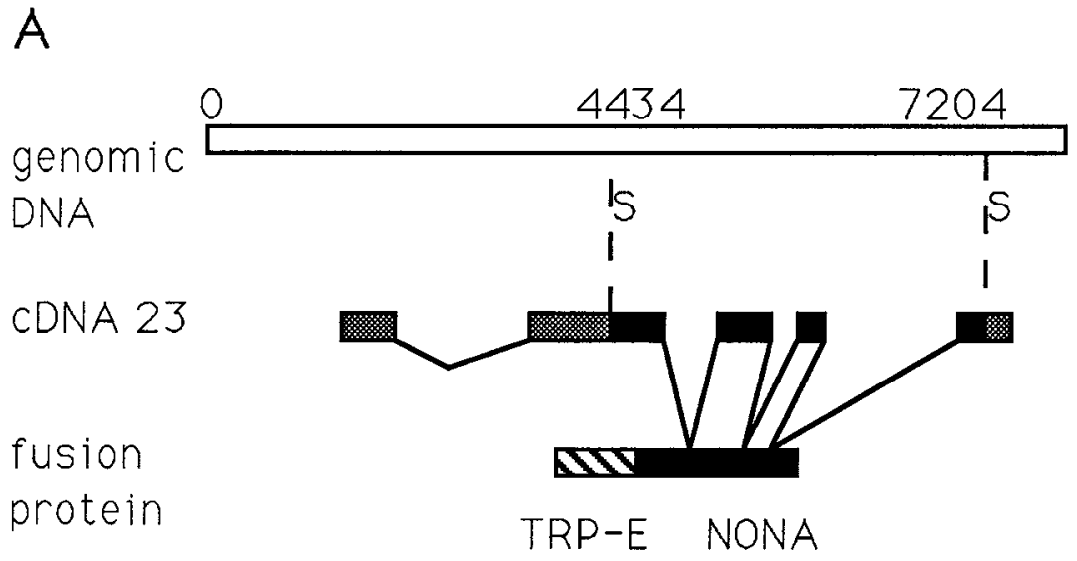

Figure 4. Production of anti-NONA antibody and its biochemical application. $A$, Schematic diagram of the fusion protein produced by the 5 ' end of the $E$. coli trpE gene (hatched bar) and the $3^{\prime}$ Sal 1 fragment of the non $A$ cDNA 23 (solid bar) in the pATH3 vector (shaded areas represent parts of the cDNA not included in the fusion construct). The TRP-E portion of the resulting protein should be approximately $36 \mathrm{kDa}$, and that for NONA portion, approximately $60 \mathrm{kDA}$. $B$, A Western blot of Drosophila head extract from Canton-S (wild-type), non $A^{H 2}$, non $A^{P T^{4}}$, non $A^{P 49}$, non $A^{P 60}$, and non $A^{d i s s}$ flies (five adults per lane); there is a single immunoreactive protein band at approximately $80 \mathrm{kDa}$. Note that the non $A^{P 14}$ allele shows a decrement of protein levels in both sexes ( $M$, males; $F$, females) compared to the band intensities in the wild-type lanes and those of the other nonA mutants. This non $A^{P I 4}$-induced decrement has been reproduced in two additional experiments.

B

Saumweber, 1989). The change from the cytoplasmic to nuclear localization of NONA is exemplified here by the staining observed approximately $12 \%$ into the animal's embryonic development (Fig. $5 A$ ) compared to that in a late third instar larva (Fig. $5 B$ ). Developmental Western analysis (see above) also showed non $A$ expression in the first and second larval instars (data not shown), stages that were not examined in tissue sections.

Immunohistochemistry with frozen sections of male and female adult flies revealed nuclear localization of the NONA antigen (see Fig. 5D, especially its inset). Signals were seen in most cells of all tissues examined; we could not determine whether

Figure 5. Immunohistochemically determined expression of the non $A$ gene product. $A$, Whole-mount of an early embryo (stage 5). $B$, Cross section through the anterior end of a late third instar larva, showing the brain $(b)$ and ventral ganglion $(v g)$. $C$, Horizontal section through an adult male head, incubated with the flow-through material from the fusion protein affinity column (see text); there is no apparent immunoreactivity. $D$, Horizontal section through the head of an adult female wild-type (Canton-S). This pattern of immunoreactivity is indistinguishable from that observed in the male fly; the nuclear nature of the signals is especially apparent in the photoreceptor cells of the eye (solid arrows), the lamina optic lobe (solid arrowhead), and the first optic chiasm (open arrow). ey, eye; la, lamina; me, medulla; $l$, lobula complex (lobula + lobula plate optic lobes). The inset in the upper right corner shows nickel chloride-intensified staining of the photoreceptor cell nuclei (solid arrows) with the non- 

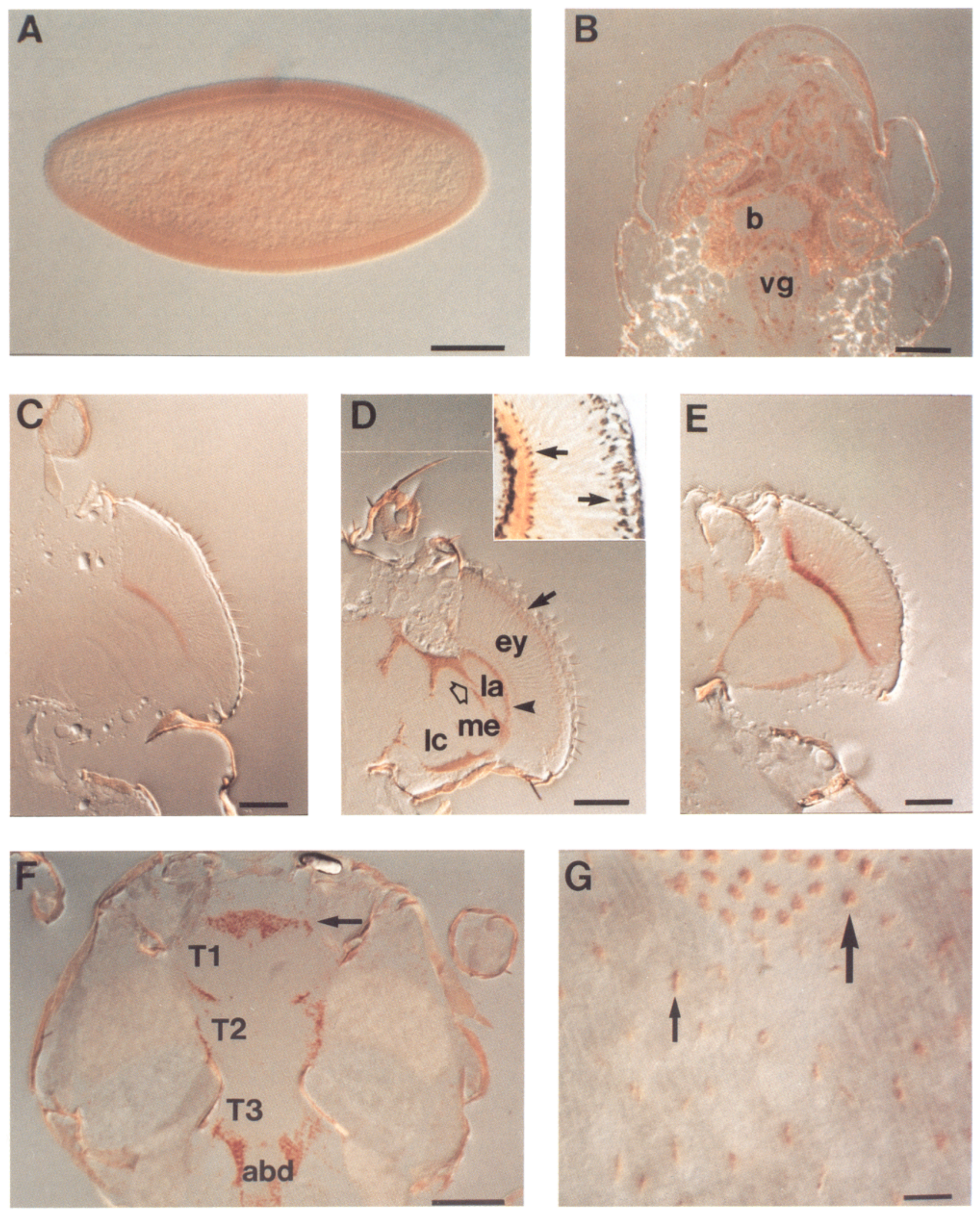

affinity-purified antibody. The latter was prepared according to the method of Kimmel et al. (1990). E, Horizontal section through an adult male $n o n A^{P 14}$ head with decreased overall staining, relative to the wild-type level. $F$, Horizontal section through an adult male wild-type (Canton-S) thorax. The solid arrow indicates nuclei of the cortical cells in the thoracic ganglia. $T 1$, prothoracic neuromere; $T 2$, mesothoracic neuromere; $T 3$, metathoracic neuromere; $a b d$, abdominal neuromere (fused in the posterior thorax to the three other ganglia just noted, which are thoracic per se). $G$, High magnification of the cells of the imaginal gut and thoracic muscle, indicating the nuclear localization of this antigen. The large arrow indicates immunoreactivity in nuclei of the gut cells, and the smaller arrow, the elongated muscle nuclei. Scale bars: $A, 50 \mu \mathrm{m} ; B, 25 \mu \mathrm{m} ; C-E, 80$ $\mu \mathrm{m} ; F, 125 \mu \mathrm{m} ; G, 10 \mu \mathrm{m}$. 
NONA immunoreactivity is present in all nuclei. The tissues in which the protein was detected included the photoreceptors and lamina of the visual system, the central brain, and the thoracic ganglia (Fig. $5 D, F$ ). Non-neural tissue was also stained, for example, in nuclei of the gut (Fig. $5 G$ ) and thoracic muscles. The follicle epithelium and the nurse cells of the female ovary, as well as the developing oocyte, also exhibited staining (not shown). The pattern of immunoreactivity in the male and female head and thoracic regions was apparently identical (data not shown). Staining appeared as if it might be more prominent in the nervous system, but this could be an artifact of neuronal cell sizes, which are relatively large. For example, the staining of muscle cell nuclei (dimensions, approximately $1 \times 3$ to 1.5 $\times 4.5 \mu \mathrm{m}$; Miller, 1950), which are smaller than those of some ganglia (diameters, $\sim 4-5 \mu \mathrm{m}$; Miller, 1950), was readily observed only at high magnification (Fig. $5 G$ ). The lack of staining observed with flow-through from the affinity column used to purify the antibody (see Materials and Methods) (e.g., Fig. 5C) suggests that the observed staining is due to immunoreactivity of the nonA gene product.

Tissue staining of flies expressing the five mutant alleles, sectioned in the same block as a wild-type control and processed together, revealed no gross detectable differences in the spatial location of the NONA antigen. Immunoreactivity was present throughout the visual system and thoracic ganglia. Sections of non $A^{P 14}$ adults, however, showed a generalized decrease in staining levels (Fig. $5 E$ ), consistent with the Western experiments. This result is a further indication of the antibody's specificity.

\section{Sequence homology to RNA-binding proteins}

$\Lambda$ s originally reported by Jones and Rubin (1990), the amino acid sequences corresponding to NONA's form I and (putative) form II proteins contain glutamine-rich regions near their amino termini and a region of highly charged residues, features characteristic of "auxiliary" domains within nucleic acid-binding proteins (Bandziulis et al., 1989). We reexamined these two polypeptides for homology with nucleotide and protein sequences in the NBRF and Gen EMBL data bases. A $27 \%$ identity, over a region of 88 amino acids, was found to the Sex-lethal (SLX) gene product of Drosophila. This is a member of a group of proteins containing one or more RNA-binding domains termed ribonucleoprotein consensus sequences (RNP-CSs) by Bandziulis et al. (1989). The significance of the motif similarities in question was not recognized earlier, primarily because the most closely related sequence (i.e., SXL; see below) had not appeared in the data bases prior to the initial report of NONA's sequence.

The approximately 80-90 amino acid RNP-CS RNA-binding motif contains an octapeptide, RNP-1 (Adam et al., 1986; Sachs et al., 1987), and an RNP-2 sextapeptide (cf. Dreyfuss et al., 1988). Two regions, within each of the two (presumptive) forms of the NONA protein (Fig. 2), matched the consensus derived by Bandziulis et al. (1989), for a group of 30 gene product sequences containing one or multiple RNP motifs. The more conserved RNP-CS, located at NONA's amino acid positions 295-373 from the N-terminus (cf. Jones and Rubin, 1990), contains six out of six amino acids at the RNP-2 site and four out of eight amino acids identical at the RNP-1 site, with the proper approximately 30 amino acid spacing between the two motifs. NONA's second RNP domain is located at amino acids $374-452$.

RNP-1 is generally a more conserved motif, among the family of proteins under consideration, than is RNP-2 (Dreyfuss et al.,
1988; Bandziulis et al., 1989; see also Discussion). The family containing RNPs includes small nuclear ribonucleoproteins (snRNPs), heterogenous ribonucleoproteins (hnRNPs), and several proteins encoded by developmentally important Drosophila genes, such as embryonic lethal abnormal visual system (elav; Rubinow et al., 1988), as well as the sex determination genes Sxl (Bell et al., 1988) and transformer-2 (tra-2; Amrein et al., 1988; Goralski et al., 1989; reviewed in Baker, 1989). The degree of sequence homology observed between NONA and the three most homologous proteins of the large family is, in order from highest to lowest, SXL, the polyA-binding proteins (PABPs), and TRA-2. There is also a good match between any of the three Drosophila proteins-NONA, SXL, TRA-2-and the PABPs.

Figure 6 shows the RNP sequence motifs found in the yeast PABP as well as the SXL, TRA-2, and NONA peptides of Drosophila, compared with the consensus for the larger family derived by Bandziulis et al. (1989). The RNP-1 and RNP-2 repeats are indicated in boldface and the characteristic aromatic amino acids within them ( $\mathrm{Tyr}, \mathrm{Phe}$ ) are underlined. These are believed to be involved in "ring stacking" interactions between protein and RNA (proposed by Kenan et al., 1991). Another notable feature of the NONA sequence is the presence of more than $50 \%$ of the conserved hydrophobic residues of the approximately 80 amino acid RNP that are thought to contribute to the folding of the protein (Kenan et al., 1991). Furthermore, the primary sequence of this portion of NONA is consistent with the secondary structural features of the U1 snRNP protein A (Nagai et al., 1990; Kenan et al., 1991), another member of the RNA-binding family.

A protein that binds single-stranded DNA as well as RNA was also revealed (from the data base search) to exhibit a significant level of sequence similarity to NONA (not shown in Fig. 6). This is a "helix-destabilizing" protein of Drosophila (Haynes et al., 1987); it is similar to NONA in the RNP domains and in a glycine-rich region as well (cf. Jones and Rubin, 1990).

\section{Discussion}

\section{Pleiotropy of behavioral phenotypes and protein expression}

The diss allele of the nonA gene leads to behavioral pleiotropy. However, this mutant is not defective in a wide range of behaviors but is specifically abnormal in the Drosophila male's courtship song and in responses to visual stimuli. The same kind of particular pleiotropy is seen in certain olfactory mutants of Drosophila, which turned out-after their isolations on odorresponse criteria alone-to be visual mutants as well (McKenna et al., 1989; Woodard et al., 1989). A further parallelism between olfactory neurogenetics and the diss/nonA connection is that the ota- 1 mutation was later shown to be an allele of a previously known "eye gene," retinal-degeneration-B(Woodard et al., 1991).

That nonA is truly a "bifunctional" gene is predicated on the ability to demonstrate that the diss and non $A$ mutations define the same genetic unit. Indeed, these mutations fail to complement one another for the visual phenotypes (Table 2), and rescue of the visual and song defects was effected by P-element transformation with the same DNA constructs (Fig. 2, Table 4). These results suggest strongly that the two kinds of genetic variants are in fact mutated either in the self-same gene or at two loci that are so closely related that they are essentially inextricable. Such a relationship could mean that there are two factors in very close proximity, whereby a "gross" genetic lesion (e.g., a small deletion) could remove or damage both of them. If that 


\begin{tabular}{llll} 
& & & \multicolumn{1}{l}{ RNP-2 } \\
PABP & $\mathbf{1}$ & SQSVENSSAS & LYVGDL-EPS \\
PABP & $\mathbf{2}$ & PSLRKKGSGN & IFIKNL-HPD \\
PABP & $\mathbf{3}$ & LEETKAHYTN & LYVKNI-NSE \\
PABP & $\mathbf{4}$ & EKMAKYQGVN & LFVKNL-DDS \\
SXL & $\mathbf{1}$ & MNDPRASNTN & LIVNYL-PQD \\
SXL & $\mathbf{2}$ & PGGESIKDTN & LYVTNL-PRT \\
TRA-2 & & SREHPQASRC & IGVFGL-NTN \\
NONA & $\mathbf{1}$ & TETKFSGRNR & LYVGNL-TND \\
NONA & $\mathbf{2}$ & ----- NATI & LRVSNL-TPF \\
& & & * * \\
CONSENSUS & & LFVGNL \\
& & & IYIKG
\end{tabular}

RNP-1

$\begin{array}{llr}\text { PABP } & \mathbf{1} & \text { S-LGYAYVXF } \\ \text { PABP } & \mathbf{2} & \text { S-KGFGFVHF } \\ \text { PABP } & \mathbf{3} & \text { L-KGFGFVXY } \\ \text { PABP } & \mathbf{4} & \text { S-KGFGFVCF } \\ \text { SXL } & \mathbf{1} & \text { S-FGYA FVDF } \\ \text { SXI } & \mathbf{2} & \text { P-RGVAFVRY } \\ \text { TRA-2 } & \text { S-RGFCFIYF } \\ \text { NONA } & \mathbf{1} & \text { D-KNETELKV } \\ \text { NONA } & \mathbf{2} & \text { H-MGEGIVEF } \\ & & \text { KGFGFVXF } \\ \text { CONSENSUS } & \text { R YA Y }\end{array}$

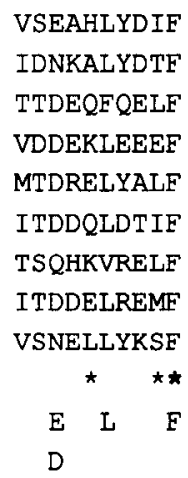

SP-IGSVSSI
SV-FGDILSS
AK-FGPIVSA
AP-YGTITSA
RA-IGPINTC
GK-YGSIVQK
NK-YGPIERI
KP-YGEISEI
EI-FGPIERA
* *
FG I
Y V

\section{NDHEAGRKAI}

EEEGAAKEAI

EKHEDAVKAV

STPEEATKAI

TSEMDSQRAI

NKREEAQEAI

EKLSDARAAK

DYHPNAEKAK

AKKSSASACL
* *
A

EQLNYTPIKG

DALNGMLLNG

EALNDSELNG

TEKNQQIVAG

KVLNGI TVRN

SALNNVIPEG

DSCSGIEVDG

RALDGSMRKG

RMCNEKCFFL

L $G$
I

\section{RVCRDAITKT \\ KAITDEN-GK \\ SLEKDAD-GK \\ KVMRTEN-GK \\ RIMRDYKTGY \\ NILRDKLTQR \\ QMVIDAQTGR \\ F------SNL \\ SITVDDR-GK \\ $\mathrm{K}$ \\ $\mathrm{R}$}

RLCRIMWSQR

QEIYVAPHLS

EKLYVGRAQK

KPLYVAIAQR

KRLKV-----

GSQPLSVRLA

RRIRVDFSIT

RQLRVRFAP-

TAS-LRPCLV

$\star \star \star$
Figure 6. Sequence similarities involving $n \cap n A$ 's putative RNA binding motifs. The unique RNP-CS-like yeast peptides PABP 1, 2, 3, and 4; SXL 1 and 2; TRA-2; and NON $A 1$ and 2 from Drosophila are shown, with the best estimates of their relative positions determined by applying the algorithm of Smith and Smith (1990). The boldface numbers indicate the separate regions of these gene products that contain the motifs in question. Below each block of comparisons is the "consensus sequence," referring to the larger family of more than 30 proteins (Bandziulis et al., 1989). The $R N P_{-}-1$ and $R N P-2$ sequence motifs are indicated in boldface. Within the NONA RNPs, conserved aromatic amino acids of RNP-1 and RNP-2 are underlined, and characteristic hydrophobic residues of the RNP domains (Kenan et al., 1991) are marked by ${ }^{*}$ or ${ }^{*}$, indicating the presence of hydrophobic amino acids in one NONA peptide or both. were the case, non $A^{d i s s}$ should be markedly abnormal at the level of mRNA and protein expression, but this mutant expresses apparently normal levels of full-length mRNA (data not shown) and protein (Fig. 4).

The results involving "transformation rescue" were not unequivocal. For example, the R11A and B transgenic lines, involving the $11 \mathrm{~kb}$ Eco RI genomic fragment, restored visual function to a better degree than they did the song phenotype (Tables 4, 5). The XS16B flies were somewhat closer to wildtype for both phenotypes, whereas line A carrying this $16 \mathrm{~kb}$ Xba I-Sac I DNA fragment effected only a partial rescue of vision and of singing (Tables 4,5 ). These inconsistencies could have resulted from "position effects" associated with the particular genomic locations of the transduced DNA insert in given transgenic lines, which can lead to lower than normal levels of the gene's expression (cf. Hazelrigg et al., 1984; Baylies et al., 1987; Jones and Rubin, 1990). Other locations might allow more normal levels of such expression.

Another case concerns the in vitro-mutated 1-STOP construct. In line $A$ of this transgenic type, the lack of rescue of visual defects was clear (Table 4; cf. Jones and Rubin, 1990), but there was some rescue of aberrant singing (Table 5). This suggests that the truncated form I protein (Fig. 2) provides suf-

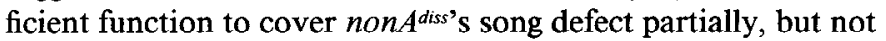
its abnormal visual responses, and that the 1-STOP B males that are not rescued for song (Table 5) suffer from a "loss-offunction" position effect.

Other pertinent examples involving Drosophila transformants illustrate robust rescue of one phenotypic defect associated with a gene's expression and less efficient rescue of a second (Gergen and Butler, 1988; Kania et al., 1990). This suggests that the piece of DNA rescuing one of the two phenotypes influenced by a locus is inherently inadequate; it might lack regulatory sequences more important for gene expression in a specific tissue (see, e.g., Pick et al., 1990). Thus, the R11 and XS16 genomic fragments could be missing "thoracic enhancers" (see below), causing relatively poor restoration of the biological activity necessary for wild-type song. Slightly larger genomic fragments, whose $5^{\prime}$ ends would extend farther distally (leftward in Fig. 2), might fully rescue both nonA-associated phenotypes.

The courtship song phenotype was more severe in flies with one dose of the non $A^{\text {diss }}$ mutation in combination with a deletion of the locus (Fig. $1 B$ ), suggesting that this allele is hypomorphic. non $A^{P 14}$ behaves as if it could be more a severe underexpressor, because of its partial noncomplementation of the non $A^{\text {diss }}$-associated song defect (Table 3). [Recall, however, that this allele leads to the least severe ERG phenotype (Table 2).] The reason that non $A^{P 14}$ males are closer to the wild-type in their singing behavior than are the diplo-X non $A^{\text {diss } / n o n A^{P 14}}$ heterozygotes (Table 3 ) is almost certainly due to dosage compensation of expression levels for X-linked genes (reviewed in Jaffe and Laird, 1986). Thus, one dose of the non $A^{p 14}$ mutation in a haplo-X fly would lead to a higher level of gene product than the equivalent dose in a diplo-X genotype. These arguments also lead to the suggestion that non $A^{\text {diss }}$ is, in terms of biological function, nearer to a null mutation than is non $A^{P 14}$. The behavioral findings involving these two alleles are consistent with this supposition and with the decreased levels of NONA protein detected in non $A^{P 14}$ extracts (see below). Whereas non $A^{\text {diss }}$ leads to apparently normal levels of gene products (see above), a mutated 
protein whose presence is readily detectable (immunologically) may nevertheless be nonfunctional; examples are provided from Drosophila neurogenetics (e.g., Baker et al., 1990).

The nonA-encoded mRNAs, and the polypeptide that we call NONA, exhibit widespread tissue distributions and expression at most stages of the life cycle. Thus, NONA is localized in the nuclei of many or all cells of the several developing and adult tissues we have examined. In early embryonic stages, however, the protein is found in the cytoplasm rather than the nucleus (Frash and Saumweber, 1989; present results).

The nonA mRNA shows a uniform distribution in the cytoplasm of early embryos (Besser et al., 1990; K. G. Rendahl and J. C. Hall, unpublished observations). However, there is a short time window during embryogenesis when the RNA localization seems restricted to the nervous system (R. Stanewsky and H. Saumweber, personal communication), though the protein is ubiquitous at this stage (Besser et al., 1990; present results). This neural specificity may indicate a critical time in development where expression is required in precursors of adult nervous system cells, especially in the visual system and thoracic ganglia (see below), given the behavioral defects seen in nonA mutants. However, it is not yet possible to make any link between the embryonic pattern of this gene's mRNA expression and the adult behavioral phenotypes.

The nonA locus belongs to an emerging category of "neurological" genes, which, although their mutated forms lead to subtle behavioral defects, or no apparent defects, have broad mRNA and protein distributions. For example, the Drosophila amyloid precursor protein-like (Appl) gene product is expressed throughout the nervous system (and, it seems, only there) all the way from embryogencsis through adult stages (Luo et al., 1990; Martin-Morris and White, 1990). Surprisingly, perhaps, $\mathrm{Appl}^{-}$mutant flies are fully viable (L. Luo and K. White, personal communication), in contrast to the case of a very similarly expressed gene, elav, which was originally defined by embryonic lethal mutations (e.g., Robinow et al., 1988).

Expression of genes in this category is not always limited to the nervous system. Examples include the period (per) and dunce $(d n c)$ genes. per is required for the functioning of the biological clock underlying circadian rhythms (Konopka and Benzer, 1971) and an ultradian rhythm associated with the male's courtship song (e.g., Kyriacou et al., 1990). The per mRNA and protein are expressed in many cells of the nervous system, as well as in a host of non-neural tissues in embryos, larvae, pupae, and adults (reviewed by Hall and Kyriacou, 1990). Mosaic studies have indicated that "head expression" of per is involved in the control of circadian rhythms (Konopka et al., 1983), whereas the gene's action in the thorax is connected to song-rhythm regulation (Hall, 1984). This again illustrates the relatively specific phenotypic defects known to be caused by per mutations. In addition, it is notable that per- mutants are completely viable (reviewed by Hall and Kyriacou, 1990). The $d n c$ gene encodes a cAMP phosphodiesterase (e.g., Chen et al., 1986), and mutations at this locus lead to defects in a variety of experiencedependent behaviors (reviewed in Quinn and Greenspan, 1984; Hall, 1986; Tully, 1987). The enzyme encoded by $d n c$ is present in all body segments of the adult and many, if not all, stages of development (Shotwell, 1983), yet $d n c$ mutants completely devoid of this gene (reviewed in Kiger and Salz, 1985) are fully viable; they do not learn (see above), exhibit one additional behavioral anomaly (Bellen and Kiger, 1987), and (as females) are sterile (e.g., Kiger and Salz, 1985).
A solely "nonA-minus" genotype is not yet available (e.g., the deletion used in the present study is also missing nearby, vital genes). Also, none of the extant mutations at the locus lead to an absence of gene product (Fig. $4 B$ ). It is possible that a nonAnull mutation would be lethal. Alternatively, one or more of the extant nonAs might produce a totally inactive protein (cf. Baker et al., 1990). Such a nonA-null mutant-perhaps the diss allele (see above)-would be analogous to the cases of $\mathrm{Appl}^{-}$, $\mathrm{per}^{-}$, and $d n \mathrm{c}^{-}$, in that the loss-of-function variant, for a widely expressed gene product, exhibits a limited array of phenotypic abnormalities. Such defects are also relatively subtle ones, that is, not involving overt developmental and morphological changes.

\section{NONA as a putative RNA-binding protein}

NONA appears to be a member of a large family of proteins containing the RNP-1 and RNP-2 sequences, which are involved in RNA binding (as demonstrated directly in some instances, e.g., Merrill et al., 1988). The RNP class of proteins is highly variable in terms of its amino acid sequences and in the roles these factors play in RNA metabolism (Bandziulis et al., 1989; Kenan et al., 1991). Thus, it is not possible now to make a specific proposal for NONA's biochemical actions in its various tissue locations.

However, it is notable that the similarity of NONA RNP sequences to those in SXL (the Sex-lethal-encoded protein) of Drosophila is the strongest of this family (Fig. 6). SXL is involved in the splicing of mRNAs that are crucial to an early stage of genetically controlled sex determination (e.g., Bell et al., 1988; Inoue et al., 1990). Although there is also good similarity of NONA to the polyA-binding proteins (Fig. 6; see also Besser et al., 1990), the resemblance of PABP sequences encoded by certain genes of human and yeast to each other is much closer. Thus, we believe that NONA is unlikely to be a PABP and suggest that it could help mediate splicing of particular mRNAs involved in the functioning of the fly's nervous system, owing to NONA's nuclear localization in neurons and the behavioral/physiological phenotypes caused by nonA mutations.

However, the work of $\mathrm{H}$. Saumweber and colleagues suggests a more general function for the NONA protein. These investigators have independently isolated the nonA gene (Besser et al., 1990); they also noted that non $A$ encodes a putative RNAbinding domain. Their method of isolation may shed light on the function of the gene: NONA in this study was identified by virtue of its presence in proteins extracted from polytene chromosomes of Drosophila larvae; such proteins were used to generate antisera, one of which was used to isolate a NONA-encoding cDNA, cloned from an expression library (Besser et al., 1990). These investigators showed further that NONA is associated (in situ) with approximately 200-300 loci in the transcriptionally active chromosome puffs of salivary glands taken from third instar larvae. In this regard, it is notable that the shift of the NONA protein from a cytoplasmic to a nuclear localization during embryogenesis occurs during gastrulation (Frasch and Saumweber, 1989), when zygotic transcription begins (Zalokar, 1976).

Additional experiments involving NONA's "binding" to larval salivary chromosome sites suggested that association of this protein with the genetic loci in question may not be through RNA-protein contacts (Saumweber et al., 1990). That NONA exhibits significant similarity to a protein that can bind to singlestranded DNA in vitro (Haynes et al., 1987) could mean that 
this gene product binds to DNA as well as, or possibly instead of, RNA in vivo.

\section{Roles of a nucleic acid-binding protein in regulating behavior}

When considering the possible function of NONA as a "gene regulatory" substance, what might the pleiotropy of both nonA mutational effects and expression mean in regard to the function of this gene in behavior and physiology?

The specificity of the behavioral defects observed in the non $A^{\text {diss }}$ mutant could be explained by analogy to the other "behavioral genes" mentioned above. Thus, it is possible that nonA's widespread expression is misleading in regard to the consequences of removing it or lowering its efficacy. A given abnormality in the gene product may, therefore, have impacts on only certain of the tissues where the protein is normally found, such as the optic lobes, which could be the focus of this (and other) non $A$ mutant's ERG deficits (see introductory remarks), and the thoracic ganglia, which are implicated in the control of Drosophila's courtship song (Hotta and Benzer, 1976; Schilcher and Hall, 1979; Hall et al., 1990). NONA may be required only in particular locations, such that only they are actually disrupted in the mutant. A further implication of this idea is that ubiquitous expression of the NONA protein could be functionally insignificant and may represent an evolutionary artifact, whereby Drosophila has not "downregulated" non $A$ in tissues where it is not needed.

An alternative to this explanation is that the relevant neural ganglia in the fly's head and thorax may be more sensitive to decrements in the amount or functioning of the protein. This notion is based on the distinct possibility that none of the nonA mutants arc null variants (notc that the stratcgics for their isolation demanded that they all be viable). Thus, in the mutants isolated so far, behavior and physiology could be "the first to go," implying that mutations that further reduce such levels would cause more severe and general effects on behaviors, viability, or both. An analogy is provided by temperature-sensitive Choline acetyltransferase ( $C h a^{t s}$ ) mutants in Drosophila. These exhibit a graded decrement in their physiology and behavior: after relatively brief heat treatments of $C h a^{t s}$ mutants, the flies exhibited aberrant ERGs and courtship behavior; lengthier exposures to the restrictive temperature caused total paralysis and, ultimately, death (Greenspan, 1980). It is easy to imagine that a "generalized" function such as the neurotransmitter metabolizing enzyme in question, as well as factors controlling transcription or RNA processing, would be vital ones, hence lethal when "turned off" totally or when unconditionally null (cf. Robinow et al., 1988; Clinc, 1989; Ingham and Nakano, 1990; Campos-Ortega and Jan, 1991).

Certain other genes of neurobiological interest in this organism have been identified initially in biochemical experiments. For instance, there are the fasciclin genes, the studies of which started with monoclonal antibodies against embryonic neural antigens (e.g., Patel et al., 1987; Zinn et al., 1988). Spatial expression of these substances during times of axonal outgrowth in the embryonic stage, and in many epidermal cells as well (Patel et al., 1987), could reasonably have led to the prediction that a null mutation in a fasciclin gene would be lethal, but this turned out not to be the case for fasI $I^{-}$variants (Elkins et al., 1990). However, in combination with a Drosophila Abelson gene $(a b l)$ mutation (cf. Henkemeyer et al., 1987), which by itself does not noticeably disrupt embryonic neural development, fasI $I^{-}$leads to gross anatomical abnormalities of the CNS in mid to late embryos (Elkins et al., 1990). By analogy, it could be that the putatively vital function encoded by non $A$ is compensated by some kind of genetic redundancy, whereby there could be one or more genes interacting with $n o n A^{+}$; only, then, in the relevant double mutant would non $A^{-}$be severely abnormal.

We are thus left with a number of intriguing questions. How does one non $A$ mutation affect the song and visual phenotypes? Is the diss allele mutated in an especially important proteincoding or regulatory region that is required for both functions, whereas the other nonA mutations lead to defects in regions required only for vision? Would more extensive phenotypic defects result from loss-of-function mutations in the nonA gene? New mutations at this locus, isolated "over" one of the extant cases, could be genotypically null. It will not only be informative to ask about the overall phenotypic effects of such mutations; they could also be valuable tools for further experiments. For example, a functionally non $A^{-}$mutant with no detectable protein would be useful as a "genetic background" for assessing expression of transduced, nonA-containing DNA fragments. Thus, does a transgenic line in which only optomotor responses, and not the ERG transients, were rescued (XS16A in Table 4) express the protein in only certain portions of the optic ganglia? Might the two lines involving the in vitro-mutated 1-STOP construct differ in their gene product levels in the thoracic ganglia, given the weak rescue of the singing defect, versus none at all (Table 5)? Even if non $A^{-}$mutations prove to be lethal, they can still be tested for their effects on behavior and physiology: mosaics could be gencrated that would cach be part non $A^{+}$, part mutant; many of these genetically mixed individuals might survive to adulthood. An analogy is provided by Acetylcholinesterase $^{+} / /$Ace $^{-}$mosaics; these were assessed, as adults, for defects in visual responses and courtship behavior (Greenspan et al., 1980; Hall et al., 1980), though a uniformly Ace $^{-}$genotype causes embryonic lethality (Hall and Kankel, 1976).

Finally, it will be important to determine whether the NONA protein actually does bind to nucleic acids, especially within the nervous system. If this can be shown, it might eventually be possible to identify "downstream" genes or gene products (cf. Baker, 1989) - that is, targets of NONA's actions-which could be involved in the control of visual, reproductive behavioral, and perhaps other phenotypes. We envisage that these further studies will reveal the nature of the NONA protein's influence on neural functions, as mediated, perhaps, by its involvement in the regulation of gene expression.

\section{References}

Adam SA, Nakagawa T, Swanson MS, Woodruff TK, Dreyfuss G (1986) mRNA polyadenylate-binding protein: gene isolation and sequencing and identification of a ribonucleoprotein consensus sequence. Mol Cell Biol 6:2932-2943.

Altschul SF, Gish W, Miller W, Myers EW, Lipman DJ (1990) Basic local alignment search tool. J Mol Biol 215:403-410.

Amrein H, Gorman M, Nöthiger RC (1988) The sex determining gene tra-2 of Drosophila encodes a putative RNA binding protein. Cell 55: 1025-1035.

Baker BS (1989) Sex in flies: the splice of life. Nature 340:521-524.

Baker NE, Mlodzik M, Rubin GM (1990) Spacing differentiation in the developing Drosophila eye: a fibrinogen-related lateral inhibitor encoded by scabrous. Science 250:1370-1377.

Bandziulis RJ, Swanson MS, Dreytuss G (1989) RNA-binding proteins as developmental regulators. Genes Dev 3:431-437.

Baylies MK, Bargiello TA, Jackson FR, Young MW (1987) Changes in abundance or structure of the per gene product can alter periodicity of the Drosophila clock. Nature 326:390-392. 
Bell LR, Maine EM, Schedl P, Cline TW (1988) Sex-lethal a Drosophila sex-determination gene, exhibits sex-specific RNA splicing and sequence similarity to RNA binding proteins. Cell 5:1037-1046.

Bellen HJ, Kiger JA Jr (1987) Sexual hyperactivity and reduced longevity of dunce females of Drosophila melanogaster. Genetics 115: $153-160$.

Bernstein AS, Neumann EK, Hall JC (1991) Temporal analysis of tone pulses within the courtship songs of two sibling Drosophila species, their interspecific hybrid, and behavioral mutants of $D$. melanogaster. J Insect Behav, in press.

Besser Hv, Schnabel P, Wieland C, Fritz E, Stanewsky R, Saumweber H (1990) The puff-specific Drosophila protein $\mathrm{Bj6}$, encoded by the gene no-on transient- $A$, shows homology to RNA binding proteins. Chromosoma 100:37-47.

Burnet B, Connolly K (1974) Activity and sexual behavior in Drosophila melanogaster. In: The genetics of behavior (van Aberdeen JHF, ed), pp 201-258. New York: Elsevier.

Campos-Ortega JA, Jan Y-N (1991) Genetic and molecular bases of neurogenesis in Drosophila melanogaster. Annu Rev Neurosci 14 399-420.

Chen CN, Denome S, Davis RL (1986) Molecular analysis of cDNA clones and the corresponding genetic coding sequences of the Drosophila dunce ${ }^{+}$gene, the structural gene for cAMP phosphodiesterase. Proc Natl Acad Sci USA 83:9313-9317.

Cline TW (1989) The affairs of daughterless and the promiscuity of developmental regulators. Cell 59:231-234.

Conover WJ (1980) Some methods based on rank. In: Practical nonparametric statistics, 2d ed, pp 213-343. New York: Wiley.

Coombe PE (1986) The large monopolar cells L1 and L2 are responsible for ERG transients in Drosophila. J Comp Physiol 159:655665.

Coombe PE, Heisenberg M (1986) The structural brain mutant $\mathrm{Vac}$ uolar medulla of Drosophila melanogaster with specific behavioral defects and cell degeneration in the adult. J Neurogenet 3:135-158.

Cowling DG, Burnet B (1981) Courtship songs and genetic control of their acoustical characteristics in sibling species of Drosophila melanogaster. Anim Behav 29:924-935.

Devercux J (1989) Program manual for the scquence analysis software package of the Genetics Computer Group. Madison, WI: University of Wisconsin Biotechnology Center.

Devereux J, Heaberli P, Smithies O (1984) A comprehensive set of sequence analysis programs for the VAX. Nucleic Acids Res 12:387395.

Dreyfuss G, Swanson MS, Pinal-Roma S (1988) Heterogeneous nuclear ribonucleoprotein particles and the pathway of mRNA formation. Trends Biochem Sci 13:86-91.

Elkins T, Zinn K, McAllister L, Hoffman FM, Goodman CS (1990) Genetic analysis of a Drosophila neural cell adhesion molecule: interaction of fasciclin $I$ and Abelson tyrosine kinase mutations. Cell $60: 565-575$.

Ewing AW (1977) Communication in Diptera. In: How animals communicate (Sebeok T, ed), pp 403-417. Bloomington, IN: Indiana UP.

Falk DR, Roselli L, Curtiss S, Halladay D, Klufas C (1984) The characterization of chromosome breaks in Drosophila melanogaster. Mutat Res 126:25-34

Frasch M, Saumweber H (1989) Two proteins from Drosophila nuclei are bound to chromatin and are detected in a series of puffs on polytene chromosomes. Chromosoma 97:272-281.

Ganetzky B, Wu CF (1982) Indirect suppression involving behavioral mutants with altered nerve excitability in Drosophila melanogaster. Genetics 100:597-614.

Gergen JP, Butler BA (1988) Isolation of the Drosophila segmentation gene runt and analysis of its expression during embryogenesis. Genes Dev 2:1179-1193.

Goralski TJ, Edstrom JE, Baker BS (1989) The sex determination locus transformer-2 of Drosophila encodes a polypeptide with similarity to RNA binding proteins. Cell 56:1011-1018.

Gorczyca M, Hall JC (1987) The Insectavox, an integrated device for recording and amplifying courtship songs of Drosophila. Drosophila Inform Serv 66:157-160.

Götz KG (1964) Optomotorische Untersuchung des visuellen Systems einiger Augenmutanten der Fruchtfliege Drosophila. Kybernetik 2: 215-221.

Greenspan RJ (1980) Mutations of choline acetyltransferase and associated neural defects in Drosophila melanogaster. J Comp Physiol $137: 83-92$
Greenspan RJ, Finn JA Jr, Hall JC (1980) Acetylcholinesterase mutants in Drosopshila and their effects on the structure and function of the central nervous system. J Comp Neurol 189:741-774.

Hall JC (1984) Complex brain and behavioral functions disrupted by mutations in Drosophila. Dev Genet 4:355-378.

Hall JC (1986) Learning and rhythms in courting, mutant Drosophila. Trends Neurosci 9:414-418.

Hall JC, Kankel DR (1976) Genetics of acetylcholinesterase in Drosophila melanogaster. Genetics 83:517-535.

Iall JC, Kyriacou C (1990) Genetics of biological rhythms in Drosophila. Adv Insect Physiol 22:221-298.

Hall JC, Tompkins L, Kyriacou CP, Siegel RW, Schilcher Fv, Greenspan RJ (1980) Higher behavior in Drosophila analyzed with mutations that disrupt the structure and function of the nervous system. In: Development and neurobiology of Drosophila (Siddiqi O, Babu P, Hall LM, Hall JC, eds), pp 425-455. New York: Plenum.

Hall JC, Kulkarni SJ, Kyriacou CP, Yu Q, Rosbash M (1990) Genetic and molecular analysis of courtship song rhythms in Drosophila. In: Developmental behavior genetics (Hahn ME, Hewitt ND, Henderson ND, Benno R, eds), pp 100-112. New York: Oxford UP.

Haynes SR, Rebbert ML, Mozer BA, Fourquignon F, Dawid IB (1987) pen repeat sequences are GGN clusters and encode a glycine-rich domain in a Drosophila cDNA homologous to the rat helix destabilizing protein. Proc Natl Acad Sci USA 84:1819-1823.

Hazelrigg T, Levis R, Rubin GM (1984) Transformation of white locus DNA in Drosophila: dosage compensation, zeste interaction and position effects. Cell 36:469-481.

Heisenberg M (1971) Isolation of mutants lacking the optomotor response. Drosophila Inform Serv 46:68.

Heisenberg M (1972) Comparative behavioral studies on two visual mutants of Drosophila. J Comp Physiol 80:119-136.

Heisenberg M, Buchner E (1977) The role of retinula cell types in visual behavior of Drosophila melanogaster. J Comp Physiol 117: $127-162$.

Heisenberg M, Wolf R (1984) Vision in Drosophila: genetics of microbehavior. Berlin: Springer.

Henkemeyer MJ, Gertler FB, Goodman W, Hoffman MF (1987) The Drosophila Abelson proto-oncogene lomolog: identification of mutant alleles that have pleiotropic effects late in development. Cell 51:821828.

Homyk T Jr, Isono K, Pak WL (1985) Developmental and physiological analysis of a conditional mutation affecting photoreceptor and optic lobe development in Drosophila melanogaster. J Neurogenet 5: $37-48$.

Hotta Y, Benzer S (1970) Genetic dissection of the Drosophila nervous system by means of mosaics. Proc Natl Acad Sci IJSA 67:1156-1163.

Hotta Y, Benzer S (1976) Courtship in Drosophila mosaics: sex-specific foci for sequential action patterns. Proc Natl Acad Sci USA 73:4154 4158.

Hudson L, Hay FC (1980) Practical immunology, 2d ed. Oxford: Blackwell.

Ingham PW, Nakano Y (1990) Cell patterning and segment polarily genes in Drosophila. Dev Growth Differ 32:563-574.

Inoue K, Hoshijima K, Sakamoto H, Shimura Y (1990) Binding of the Drosophila Sex-lethal gene product to the alternative splice site of transformer primary transcript. Nature 344:461-463.

Jaffe E, Laird C (1986) Dosage compensation in Drosophila. Trends Genet 2:316-321.

Jones KR, Rubin GM (1990) Molecular analysis of no-on-transient $A$, a gene required for normal vision in Drosophila. Neuron 4:711723 .

Kania MA, Bonner AS, Duffy JB, Gergen JP (1990) The Drosophila segmentation gene runt encodes a novel nuclear regulatory protein that is also expressed in the developing nervous system. Genes Dev 4:1701-1713.

Kenan DJ, Query CC, Keene JD (1991) RNA recognition: towards identifying determinants of specificity. Trends Biochem Sci, 16:214 220.

Kiger JA, Salz HK (1985) Cyclic nucleotide metabolism and physiology of the fruit fly Drosophila melanogaster. Adv Insect Physiol 18: $142-179$.

Kimmel BE, Heberlein U, Rubin GM (1990) The homeo domain protein rough is expressed in a subset of cells in the developing Drosophila eye where it can specify photoreceptor cell subtype. Genes Dev 4:712-727.

Kleid DG, Yansura D, Small B, Dowbenko D, Moore DM, Grubman 
MJ, McKercher PD, Morgan DO, Robertson BH, Bachrach HL (1981) Cloned viral protein for foot and mouth disease: responses in cattle and swine. Science 214:1125-1129.

Konopka R, Wells S, Lee T (1983) Mosaic analysis of a Drosophila clock mutant. Mol Gen Genet 190:284-288.

Konopka RJ, Benzer S (1971) Clock mutants of Drosophila melanogaster. Proc Natl Acad Sci USA 68:2112-2116.

Kulkarni SJ, Hall JC (1987) Behavioral and cytogenetic analysis of the cacophony courtship song mutant and interacting genetic variants in Drosophila melanogaster. Genetics 116:461-475.

Kulkarni SJ, Steinlauf AF, Hall JC (1988) The dissonance mutant of Drosophila melanogaster: isolation, behavior and cytogenetics. Genetics 118:267-285.

Kyriacou CP, van den Berg MJ, Hall JC (1990) Drosophila courtship song cycles in normal and period mutant males revisited. Behav Genet 20:617-644.

Lindsley DL, Zimm G (1990) The genome of Drosophila melanogaster, Pt 4. Drosophila Inform Serv 68:17.

Lipshitz HD, Kankel DR (1985) Specificity of gene action during central nervous system development in Drosophila melanogaster: analysis of the lethal(l)optic ganglia reduced locus. Dev Biol 108:5677.

Luo L, Martin-Morris LE, White K (1990) Identification, secretion, and neural expression of APPL, a Drosophila protein similar to human amyloid protein precursor. J Neurosci 10:3849-3861.

Martin-Morris L, White K (1990) The Drosophila transcript encoded by the $\beta$-amyloid protein precursor-like gene is restricted to the nervous system. Development 110:185-195.

McKenna M, Monte P, Helfand SL, Woodard C, Carlson J (1989) A simple chemosensory response in Drosophila and the isolation of $a c j$ mutants in which it is affected. Proc Natl Acad Sci USA 86:81188122.

Merrill BM, Stone KL, Cobianchi F, Wilson SH, Williams KL (1988) Phenylalanines that are conserved among several RNA-binding proteins form part of a nucleic-acid binding pocket in the Al heterogeneous nuclear ribonucleoprotein. J Biol Chem 263:3307-3313.

Miller A (1950) The internal anatomy and histology of the imago of Drosophila melanogaster. In: Biology of Drosophila (Demerec M, ed), pp 420-531. New York: Wiley.

Myers AM, Crivellone MD, Tzagoloff A (1987) Assembly of the mitochondrial membrane system MRP1 and MRP2, two yeast nuclear genes coding for mitochondrial ribosomal proteins. J Biol Chem 262: 3388-3397.

Nagai K, Oubridge C, Jessen TH, Li J, Evans PR (1990) Crystal structure of the RNA-binding domain of the U1 small nuclear ribonucleoprotein A. Nature 348:515-520.

O'Tousa JE (1990) Genetic analysis of phototransduction in Drosophila. Semin Neurosci 2:207-215.

Pak WL (1975) Mutations affecting the vision of Drosophila melanogaster. In: Handbook of genetics, Vol 3 (King RC, ed), pp 703733. New York: Plenum.

Pak WL (1991) Molecular genetic studies of photoreceptor function using Drosophila mutants. Prog Clin Biol Res 362:1-32.

Pak WL, Grossfield H, Arnold S (1970) Mutants of the visual pathway of Drosophila melanogaster. Nature 227:518-520.

Pak WL, Grabowski RS (1978) Physiology of the visual and flight systems. In: The genetics and biology of Drosophila, Vol 2a (Ashburner M, Wright TRF, eds), pp 553-604. London: Academic.

Patel NH, Snow PM, Goodman CS (1987) Characterization and cloning of fasciclin III: a glycoprotein expressed on a subset of neurons and axon pathways in Drosophila. Cell 48:975-988.

Pearson WR, Lipman DJ (1988) Improved tools for biological sequence comparison. Proc Natl Acad Sci USA 85:2444-2448.

Pick L, Schier A, Affolter M, Schmidt-Glenewinkel T, Gehring WJ
(1990) Analysis of the $f t z$ upstream element: germ layer-specific enhancers are independently autoregulated. Genes Dev 4:1224-1239.

Quinn WG, Greenspan RJ (1984) Learning and courtship in Drosophila: two storics with mutants. Annu Rev Neurosci 7:67-93.

Rendahl KG, Hall JC (1991) Neurogenetics of the nonA locus of $D$. melanogaster, a gene involved in courtship and visual behaviors. J Neurogenet $7: 142$

Rio DC, Laski FA, Rubin GM (1986) Identification and immunological analysis of biologically active Drosophila P element transposase. Cell 44:21-32.

Robinow S, Campos AR, Yao KM, White KW (1988) The elav gene product of Drosophila, required in neurons, has three RNP concensus motifs. Science 242:1570-1572.

Ruther U, Muller-Hill B (1983) Easy identification of cDNA clones. EMBO J 2:1791-1794.

Sachs AB, Davis RW, Kornberg RD (1987) A single domain of yeast poly $(\mathrm{A})$ binding protein is necessary and sufficient for RNA binding and cell viability. Mol Cell Biol 7:3268-3276.

Saumweber H, Frasch M, Korge G (1990) Two puff specific-proteins bind within the $2.5 \mathrm{~kb}$ upstream region of the Drosophila melanogaster Sgs-4 gene. Chromosoma 99:52-60.

Schalet AP (1986) The distribution of and complementation relationships between spontaneous X-linked recessive lethal mutations recovered from crossing long-term laboratory stocks of Drosophila melanogaster. Mutat Res 163:115-144.

Schilcher Fv, Hall JC (1979) Neural topography of courtship song in sex mosaics of Drosophila melanogaster. J Comp Physiol 129:85-95.

Shotwell SL (1983) Cyclic adenosine 3':5'-monophosphate phosphodiesterase and its role in learning in Drosophila. J Neurosci 3:739747.

Smith DP, Stammes MA, Zuker CS (1991) Signal transduction in the visual system of Drosophila. Annu Rev Cell Biol, in press.

Smith RF, Smith T (1990) Automatic generation of primary sequence patterns from sets of related protein sequences. Proc Natl Acad Sci USA 87:118-122.

Sturtevant AH (1945) A gene in Drosophila melanogaster that transforms females into males. Genetics 30:297-299.

Surdej P, Got C, Miassod R (1990) Developmental expression pattern of a $800 \mathrm{~kb}$ DNA continuum cloned from the Drosophila $\mathrm{X}$ chromosome 14B-15B region. Biol Cell 68:105-118.

Tully T (1987) Drosophila learning and memory revisited. Trends Neurosci 10:330-335.

Watanabe T, Kankel DR (1990) Molecular cloning and analysis of l(l)agre, a locus of Drosophila melanogaster with prominent effects on the postembryonic development of the central nervous system. Genetics 126:1033-1044.

Wheeler DA, Fields WA, Hall JC (1988) Spectral analysis of Drosophila courtship songs: $D$. melanogaster, $D$. simulans, and their interspecific hybrid. Behav Genet 18:675-703.

Wheeler DA, Kulkarni SJ, Gailey DA, Hall JC (1989) Spectral analysis of courtship songs in behavioral mutants of Drosophila melanogaster. Behav Genet 19:503-528.

Woodard C, Huang T, Sun H, Helfand SL, Carlson J (1989) Genetic analysis of olfactory behavior in Drosophila: a new screen yields the ota mutants. Genetics 123:315-326.

Woodard C, Alcorta E, Carlson J (1991) The rdgB gene of Drosophila: a link between vision and olfaction. J Neurogenet, in press.

Zalokar M (1976) Audioradiographic study of protein and RNA formation during early development of Drosophila eggs. Dev Biol 49: $425-437$.

Zinn K, McAllister L, Goodman CS (1988) Sequence analysis and neuronal expression of fasciclin I in grasshopper and Drosophila. Cell 53:577-587. 